6.

Derecho constitucional 

Revista de Derecho

de la Pontificia Universidad Católica de Valparaíso

XXXII (Valparaíso, Chile, $1^{\text {er }}$ Semestre de 2009)

[pp. 443 - 484]

\title{
LA FUERZA NORMATIVA DE LA CONSTITUCIÓN Y EL SISTEMA DE FUENTES DEL DERECHO*
}

["The Constitution's Force of Law and the System of Sources of Law"]

\author{
Eduardo Aldunate Lizana** \\ Pontificia Universidad Católica de Valparaíso
}

\begin{abstract}
RESUMEN
El artículo expone los significados corrientes de la idea de fuerza normativa de la constitución en la doctrina y jurisprudencia nacionales y examina los aspectos discutibles de la invocación de este principio, sus orígenes y su verdadero sentido en el ámbito del derecho constitucional, así como el alejamiento de la praxis institucional de una verdadera fuerza normativa de la Constitución en diversos casos. Concluye examinando de manera crítica el efecto de la invocación del principio de fuerza normativa de la Constitución sobre el sistema de fuentes.

Palabras clave: Fuentes del Derecho - Normatividad - Teoría de la constitución.
\end{abstract}

\begin{abstract}
This article presents the ordinary meanings of the idea of the constitution's force of law in the national doctrine and jurisprudence, and examines the arguable aspects of the invocation of this principle, its origins and its real meaning in the constitutional law scope, as well as the deviation from the institutional praxis from a true constitution's force of law in several cases. It finishes with a critical revision of the effect of invoking the constitution's force of law principle on the system of sources.

KEYwORDs: Sources of Law - Regulation - Theory of the constitution.
\end{abstract}

* Artículo desarrollado en el marco del proyecto de investigación Fondecyt No 1080618, bajo la conducción del investigador responsable Eduardo Cordero Quinzacara, profesor de Derecho administrativo de la misma Escuela.

** Profesor titular de Derecho constitucional en la Escuela de Derecho de la Pontificia Universidad Católica de Valparaíso. Dirección postal: Escuela de Derecho, Pontificia Universidad Católica de Valparaíso, Av. Brasil 2950, Valparaíso, Chile. Correo electrónico ealdunat@ucv.cl 


\section{PLANTEAMIENTO DEL PROBLEMA Y OBJETO DEL PRESENTE TRABAJO}

Desde hace un tiempo se ha hecho usual, tanto en la doctrina como en la jurisprudencia nacional ${ }^{1}$, la referencia a la fuerza normativa de la constitución ${ }^{2}$. Se maneja un concepto más o menos general de la misma -frecuentemente identificado con la idea de su eficacia directa- y de su efecto sobre el sistema de fuentes, calificado como efecto de irradiación. Sin embargo, ninguna de ambas nociones recibe una delimitación o unos contornos conceptuales precisos, ni son analizados desde el punto de vista de sus consecuencias, tanto para la constitución misma como para el sistema de fuentes. En especial, no se discuten las consecuencias negativas que para la propia fuerza normativa de la constitución puede tener un manejo generoso o vago del significado de esta idea, ni de las dificultades que plantea el postulado de una extensión irrestricta de sus efectos normativos en el sistema de fuentes. A más tardar con el despliegue de la competencia otorgada al Tribunal Constitucional por la reforma constitucional del año 2005, para conocer de la inaplicabilidad de preceptos legales cuya aplicación pueda resultar inconstitucional en una gestión pendiente, estas preguntas se han desplazado desde el campo de la teoría constitucional y de la teoría del derecho, hacia una dimensión eminentemente práctica.

El presente trabajo tiene por objeto precisar el sentido de la noción de fuerza normativa de la constitución y la función que ella cumple, tanto para la constitución como para el sistema de fuentes del ordenamiento jurídico cuya validez reposa en ella. Con este fin se examinará, en primer lugar, el estado de la cuestión en la doctrina y en la jurisprudencia constitucional, y los problemas que plantea, para luego pasar a estudiar el punto de partida del tópico, su sentido original en el contexto de la teoría de la constitución y el resultado de aplicar dicho sentido a la forma cómo se estructura nuestro sistema de fuentes para, finalmente, precisando el concepto de normatividad desde el punto de vista jurídico, discutir dos concepciones de la constitución y sus correspondientes consecuencias para el sistema de fuentes del derecho.

${ }^{1} Y$ también en el derecho comparado, lo que no se tratará en este artículo.

${ }^{2}$ En adelante, las referencias a la Constitución, con mayúscula, se reservarán para aludir a nuestra carta vigente; con minúscula, a las distintas categorías conceptuales que se abarcan bajo la denominación "constitución". 


\section{EL ESTADO DE LA CUESTIÓN EN LA DOCTRINA Y LA JURISPRUDENCIA CHILENAS}

A la fecha del presente trabajo (inicios del año 2009) la idea o invocación de la fuerza normativa de la constitución es, al menos en el planto terminológico, una cuestión pacífica. La doctrina hace regular alusión al tópico: en 1998 Luz Bulnes Aldunate, en 2001 Miguel Ángel Fernández González y en 2004 Rodrigo Aros Chia publicaron sendos artículos cuyo título es, precisamente, La fuerza normativa de la Constitución. Obras de diversos autores, por su parte, contiene afirmaciones frecuentes y no contestadas respecto de uno o más de los elementos que se discuten más abajo, y que se estiman comprendidos dentro de este tópico ${ }^{3}$. Lo mismo sucede con la jurisprudencia del Tribunal Constitucional, que junto con utilizar de manera usual términos tales como eficacia directa, interpretación conforme de la Constitución y otras similares, emplea la expresión fuerza normativa (de la Constitución) en diversos fallos, como sucede por ejemplos en los roles $\mathrm{No}^{\circ} 346,558,591,740,815,976$. También es posible encontrar el uso de esta expresión en la Corte Suprema, por ejemplo en su fallo rol No 5420-08, cuya importancia se comentará más adelante.

Este difundido uso de la expresión no va acompañado, sin embargo, de uniforme comprensión respecto de sus contenidos. Dicho de otro modo, cuando en nuestra comunidad jurídica se habla de fuerza normativa de la constitución, se entiende que hablamos más o menos de lo mismo: pero la varianza entre el "más" y el "menos" de esto mismo es significativa. Bajo la referencia a la fuerza normativa de la constitución ha sido posible encontrar los siguientes contenidos, ya sea respecto de su significado, ya sea respecto de sus consecuencias en el plano metodológico o institucional.

\section{La fuerza normativa como eficacia directa de la Constitución.}

En primer lugar, de manera indiscutida y general, la afirmación de la fuerza normativa de la constitución se asocia e incluso llega a identificarse con la idea de la constitución como fuente de derecho directamente aplicable, bajo alusión a la Carta de 1980 como norma directamente

${ }^{3}$ Cea Egaña. José Luis, Derecho constitucional chileno (2a edición actualizada, Santiago, Ediciones de la Universidad Católica de Chile, 2008), p. 244; "aplicación inmediata y carácter imperativo de su contenido”, según Verdugo Marinkovic, Mario - Pfeffer Urquiaga, Emilio - Nogueira Alcalá, Humberto, Derecho constitucional (reimpresión de la 2a edición, Santiago de Chile, Editorial Jurídica de Chile, 2005), I, p. 131; "obligatoriedad de la Constitución", en Silva Bascuñan, Alejandro, Tratado de Derecho constitucional (Santiago de Chile, Editorial Jurídica de Chile, 1997), IV, p. 133 ss., etc. 
aplicable, o bien como referencia al "principio de vinculatoriedad directa" o "inmediata" de la Constitución. Esta calidad, la de ser las disposiciones constitucionales directamente aplicables, es derivada del artículo $6^{\circ}$ inciso $2^{\circ}$ C.Pol. Este enunciado puede desglosarse en la afirmación de que las disposiciones constitucionales i) son verdaderas normas jurídicas ${ }^{4}$; ii) obligatorias ${ }^{5}$; iii) no constituyen meros programas, idearios o planes ${ }^{6}$; y iv) su transgresión debe conducir a la correspondiente sanción ${ }^{7}$.

La afirmación de la constitución como norma directamente aplicable no va esencialmente aparejada, como suele pensarse, a la idea de que no es necesaria la mediación legislativa que desarrolle sus disposiciones, sino que quiere decir que, incluso en aquellos casos en que se precisa de la actividad legislativa, la constitución puede ser aplicada como fuente para determinar la correspondiente omisión y activar los mecanismos de control asociados.

\section{La fuerza normativa como imperativo de interpretación conforme.}

Una segunda consecuencia aparejada a la idea de fuerza normativa es la afirmación de que, allí donde un órgano jurisdiccional se enfrenta a un caso de interpretación de la ley, debe optar por aquella alternativa de interpretación que se conforme -o que "mejor" se conforme- con la Constitución. La interpretación conciliadora o conforme es, según Zapata Larraín, una alternativa menos drástica que la declaración de inconstitucionalidad de un precepto, se expresa en las denominadas sentencias interpretativas (como medio especialmente idóneo para mostrar respecto del legislador una "deferencia razonada”), y se fundamentaría en la presunción de constitucionalidad que debe predicarse respecto del actuar del legislador ${ }^{8}$. La idea de fuerza normativa como antecedente de la interpretación conforme de la Constitución se expresa en la sentencia recaída en el rol 558-06, c. 7: "Que la llamada interpretación conciliadora de la Constitución deriva de su fuerza normativa, asi como de su vinculación y cumplimiento inmediatos, tal como se desprende del articulo $6^{\circ}$, incisos primero y segundo, de la Carta

\footnotetext{
${ }^{4}$ Bulnes Aldunate, Luz, La fuerza normativa de la Constitución, en Revista Chilena de Derecho (Pontificia Universidad Católica, 1998), Número Especial, p. 137.

${ }^{5}$ Cea Egaña. José Luis, Sistema constitucional de Chile. Sintesis crítica (Valdivia, Universidad Austral de Chile, 1999), p. 180; Bulnes Aldunate, cit. (n. 4).

${ }^{6}$ Cea Egaña, Sistema constitucional, cit. (n. 5).

${ }^{7}$ Fernández González, Miguel Ángel, La fuerza normativa de la Constitución, en Revista de Derecho Público 63 (Universidad de Chile, 2001), p. 78.

${ }^{8}$ Zapata Larraín, Patricio, Justicia constitucional (Santiago de Chile, Editorial Jurídica de Chile, 2008). pp. 326, 327, con referencias a Teodoro Ribera, en Estudios Públicos 34 (1989), p. 225.
} 
Fundamental.I Un reputado autor (Germán Bidart Campos, El Derecho de la Constitución y su Fuerza Normativa, EDIAR, primera reimpresión, p. 389) asevera que "si es cierto que la fuerza normativa sirve para descalificar transgresiones, su rol fundamental radica en procurar que no haya transgresiones; en que la Constitución se acate, se cumpla y alimente afirmativa y positivamente a todo el mundo jurídico-político. Tal vez resida allí la razón de la aludida obligación judicial de intentar la compatibilización con la Constitución, y sólo después de fracasado ese intento, declarar que una norma o un acto son inconstitucionales".

En el considerando siguiente del mismo fallo, el Tribunal deslinda el campo de aplicación de la interpretación conforme, señalando que no corresponde buscar dicha interpretación en el caso de procedimientos en que se ejerce la acción de inaplicabilidad; y dice: "Que, al pronunciarse sobre la inaplicabilidad de un precepto legal, esta Magistratura decide si su aplicación en una determinada gestión judicial resulta contraria a los fines previstos en la Constitución -estimando la relación jurídico-procesal en que incide-y, por ende, su examen es particular, no se dirige a calificar la legitimidad constitucional del enunciado normativo en abstracto. No le corresponde en ese proceso, entonces, discernir otras interpretaciones de la ley diversas a las que derivan de la forma en que ella se aplica en ese caso concreto. Circunscrita la litis a las pretensiones de las partes, carece el Tribunal de facultad para buscar una interpretación de la ley conforme a la Constitución $y$ debe limitarse, como se ha dicho, a establecer si su aplicación especifica se atiene o concuerda con aquélla"10.

${ }^{9}$ En tanto, la misma reflexión sobre interpretación conforme es presentada en la sentencia rol No 681-06 (de fecha anterior al rol 558-06), como manifestación de respeto al legislador: "80 Que, tal y como lo han reconocido uniformemente la doctrina y la jurisprudencia comparadas, el respeto hacia la labor que desarrolla el legislador obliga al Tribunal Constitucional, en su función de contralor de la constitucionalidad de la ley, a buscar, al menos, alguna interpretación del precepto cuestionado que permita armonizarlo con la Carta Fundamental y sólo en el evento de no ser ello posible, unido a la necesidad de cautelar integralmente la plena vigencia de los principios de supremacía constitucional, igualdad ante la ley y certeza jurídica, resultará procedente y necesaria la declaración de inconstitucionalidad". Como sea que se entienda la idea de fuerza normativa de la Constitución, ella no parece del todo conciliable con la doctrina de la deferencia razonada respecto del legislador, en la medida en que ésta conlleva de manera implícita la idea de no extender el parámetro de control de constitucionalidad en virtud de consideraciones de cualquier tipo, pero en todo caso no relacionadas con el despliegue de la normatividad de la Constitución".

${ }^{10} \mathrm{El}$ destacado es mío [E.A.L.]. 
3. La fuerza normativa como fundamento de reglas especiales de interpretación.

Un tercer aspecto que se menciona dentro del ámbito de la fuerza normativa de la constitución es la afirmación de que de ella se desprenden reglas especiales de interpretación. Al respecto el Tribunal Constitucional hace suyo, en su sentencia recaída en rol No 591 ("Píldora I"), un postulado de Cea Egaña, que transcribe en su considerando 90: "Primero, aunque toda la Constitución es parte de un sistema jurídico y, como tal, susceptible de ser interpretada según los cánones comunes de la hermenéutica jurídica, también es cierto que toda Constitución no es igual a las demás normas integrantes de aquel sistema, porque es única, básica o fundamental; suprema o máxima; escueta o general; teleológica y no sólo declarativa; auto aplicativa o de fuerza normativa propia e inmediata, etc. Por esas cualidades exclusivas, razonable resulta no interpretar la Constitución como cualquier precepto de un ordenamiento jurídico, sea una ley, un código o reglamento."

El postulado es curioso, ya que se predica aquí, como elemento para justificar una interpretación diferenciada, precisamente un rasgo cuya afirmación respecto de la constitución la pone en el mismo plano que el de otras fuentes de normatividad directa (ley, código, reglamento). Puede decirse que el vínculo entre fuerza normativa y reglas especiales de interpretación constitucional está muy vagamente formulado en nuestra doctrina, y roza hacia la tautología: "Es dentro de este texto y contexto, en donde debe observarse la Fuerza Normativa (sic) de la constitución, es decir, sobre la base de reconocer que los diversos preceptos constitucionales tienen de [sic] motu proprio una energía normativa, aun cuando la interpretación que de ella se haga sea diferente, lo cual incide directamente en la aplicación que de ella se haga [...]"11.

\section{El efecto de irradiación.}

Quizás el más gravitante efecto adscrito al ámbito conceptual de la fuerza normativa de la constitución sea el efecto de irradiación de la Constitución en el ordenamiento jurídico en general. Ha señalado al respecto el Tribunal Constitucional en su sentencia en causa rol No 976-07, conside-

${ }^{11}$ Aros Chia, Rodrigo Marcelo, La fuerza normativa de la Constitución: Un principio vinculante de la judicatura constitucional, en Revista de Derecho Público 66 (Universidad de Chile, 2004), p. 155. Con algo de mayor claridad señala, en pp. 156 y 157 , y en un sentido que apunta al origen del problema de la fuerza normativa de la Constitución que "[...] existen ciertas finalidades particulares que deben ser realizadas en el marco del proceso interpretativo, las cuales se traducen en velar porque efectivamente el ordenamiento Jurídico Constitucional tenga una aplicación real y efectiva”. 
rando 35": "Que lo explicado en el considerando precedente resulta coherente con la fuerza normativa que singulariza la Carta Fundamental, caracteristica conforme a la cual ésta se irradia al ordenamiento juridico entero, al punto que ninguna de sus disposiciones puede quedar al margen de o en pugna con la supremacía que es propia de ella. En este sentido, pertinente es recordar la reflexión de autorizada doctrina, en uno de cuyos libros se lee que esa cualidad de la Ley Suprema: "apareja necesariamente estar dotada de fuerza normativa para operar sin intermediación alguna, y obligación (para todos los operadores gubernamentales y para los particulares en sus relaciones "inter privatos") de aplicarla, cumplirla, conferirle eficacia, no violarla -ni por acción ni por omisión-" Germán Jr. Bidart Campos: El Derecho de la Constitución y su Fuerza Normativa, Ediar, Buenos Aires, 1995, pp. 88-89".

Este efecto de irradiación se proyecta en particular al sistema de fuentes que regula las relaciones entre particulares. A la idea de aplicación directa de la Constitución (el modo de su normatividad, si se quiere) se agrega la afirmación de que ella obliga a todos, tanto órganos públicos como a particulares (en la extensión de su normatividad), dando lugar a la recepción en Chile del denominado efecto horizontal de los derechos fundamentales. Esta afirmación de vigencia directa de la Constitución usualmente no va acompañada de una reflexión sobre la posible distinción que puede tener la idea de aplicación directa de la Constitución en uno u otro caso, desde el punto de vista de las sanciones aplicables (en un caso, en el ámbito de la juridicidad, en el otro, en el ámbito de la libertad) y desde el de las fuentes del derecho. ${ }^{12}$ Se volverá a examinar este punto en el párrafo sobre los problemas que plantea la doctrina de la fuerza normativa de la constitución.

\section{La fuerza normativa como fundamento del control difuso.}

A partir de la afirmación de la fuerza normativa como eficacia directa de la constitución, y su consiguiente incorporación al sistema de fuentes, una de las conclusiones que cae con mayor peso es que cada órgano jurisdiccional debe resolver en conformidad a la integración de dicho sistema resolviendo, en caso de antinomias entre fuentes subconstitucionales y constitucionales, a favor de las segundas. Este argumento, que está en la base del nacimiento del judicial review en los Estados Unidos, sitúa la idea de eficacia directa en su correcto lugar, como elemento dentro del ámbito o contenido de la jurisdicción como potestad del órgano jurisdiccional. Si lo que se afirma es que la constitución es obligatoria para todos, y que

${ }^{12}$ A fin de no repetir conceptos aquí, remito al lector al capítulo XI de mi obra Derechos fundamentales (Santiago, LegalPublishing, 2009), pp. 211-224. 
su carácter vinculante no está sujeto a condiciones de las que dependa su eficacia ni está sometido a la necesidad de una mediación por la vía de otras fuentes o actos normativos, la única conclusión posible es que dicho carácter obligatorio e inmediato también lo tiene la constitución al ser considerada por el juez de cualquier instancia o recurso que haya de resolver. El argumento que suele enfrentarse a esta postura es que, habiendo concentrado nuestro sistema constitucional el control de constitucionalidad en el Tribunal Constitucional, no cabe a los jueces pronunciarse sobre la constitucionalidad de las leyes. Este argumento, que obedece a un error en la calificación de lo que podría hacer el juez en este ámbito, y lo que hace el Tribunal Constitucional, se rebate más abajo; valga decir aquí que ello implica tanto como sostener que, si bien la Constitución despliega su fuerza normativa como vinculación directa sobre todos, sin condiciones ni requisitos adicionales, justo el juez, o el órgano jurisdiccional, para dar efecto a la Constitución, para acoger su carácter obligatorio (cuando éste es relevante, al presentarse la respectiva antinomia) está sujeto al requisito de accionar de inaplicabilidad por inconstitucionalidad, y a la condición de que dicha acción sea acogida.

En un contexto previo a la reforma del año 2005, Miguel Ángel Fernández González (2001), José Ignacio Martínez Estay (2003) y Lautaro Ríos Alvarez (2002) se han pronunciado a favor de la tesis de que el propio juez del fondo decida la antinomia que pueda surgir entre la Constitución y un precepto infraconstitucional. El argumento aportado sigue, en todos los casos, la idea central de la eficacia directa de la Constitución y del sinsentido que se produce en afirmar la vigencia directa de la Constitución de acuerdo a los artículos $6^{\circ}$ incisos $1^{\circ}$ y $2^{\circ}$, para luego extraer del ámbito de esta afirmación al órgano jurisdiccional. En el caso del trabajo de Fernández Gonzalez, su fundamentación es de particular interés ya que, aun cuando desarrollada durante la vigencia del antiguo artículo 80 C.Pol., que otorgaba a la Corte Suprema la atribución de declarar la inaplicabilidad de un precepto legal por ser contrario a la Constitución, puede ser aplicada después de la reforma del año 2005, vigente la competencia del Tribunal Constitucional para conocer de la acción de inaplicabilidad conforme al artículo 93 inciso $1^{\circ}$ No 6 . Esta fundamentación radica en que, mientras que en otros sistemas el otorgamiento de una competencia de este tipo al órgano de jurisdicción constitucional es imperativa para el tribunal que considera que existe una contradicción entre la Constitución y un precepto infraconstitucional, en el caso chileno no existe dicho imperativo. Antes de la reforma del ańo 2005 -en el contexto en que escribe Fernández González- porque el juez no tiene ni siquiera la posibilidad de deducir una acción de inaplicabilidad; después de la reforma - y por esto se estima 
vigente en esencia este argumento- porque el artículo 93 inciso $11^{\circ}$ señala que la cuestión podrá ser planteada por cualquiera de las partes o por el juez que conoce del asunto. De este modo, se trata de una facultad, y no de un deber. Si el juez hace uso de esta libertad que la Constitución le otorga en el ejercicio de sus atribuciones, y opta por no deducir la acción ¿̨debe entenderse que ha de aplicar el precepto infraconstitucional que considera inconstitucional? ¿ $\mathrm{O}$ debe entenderse que en realidad no tiene libertad para decidir y que debe plantear la cuestión siempre que surja la duda, lo que es decir, siempre que sea relevante (porque en las demás hipótesis carece de sentido y aplicación práctica)? Ninguna de las ambas conclusiones parece sustentable a la luz del artículo $6^{\circ}$ y el artículo 93 inciso $11^{\circ}$ C.Pol.

\section{La fuerza normativa como elemento de la teoría de las inconstitucio-} nalidades por omisión.

Ocasionalmente, la fuerza normativa es mencionada como elemento de la construcción teórica destinada a sostener la existencia de inconstitucionalidades por omisión; así sucede, por ejemplo, en el caso del trabajo de Aros Chia ${ }^{13}$. Esta construcción se relaciona tanto con el primero de los tópicos señalados (aplicación de la constitución incluso en ausencia de los preceptos legales que desarrollen sus instituciones cuando ello es necesario) como con el tópico siguiente, en la medida en que la construcción de la teoría de las inconstitucionalidades por omisión sólo tiene sentido unida a la afirmación de potestades, a favor del órgano encargado de velar por la fuerza normativa de la constitución, para suplir las omisiones, como sucede por ejemplo con la facultad de dictar disposiciones provisionales en el caso del Tribunal Constitucional Federal alemán ("einstweilige Anordnungen") ${ }^{14}$.

7. La fuerza normativa como argumento para la configuración e interpretación de la competencia en la jurisdicción constitucional.

Bajo la idea de fuerza normativa de la constitución se han propuesto o amparado diversas consecuencias relacionadas con la extensión de las competencias del Tribunal Constitucional, o con la forma como éste hace ejercicio de las mismas.

a) En su trabajo del año 1998, Luz Bulnes Aldunate plantea, como correcta doctrina, dentro de las manifestaciones de la fuerza normativa

${ }^{13}$ Aros Chia, cit. (n. 11), pp. 148, 149.

${ }^{14}$ Lo anterior respecto de las omisiones propiamente tales como ausencia de toda actividad legislativa, distinguible de la existencia de vacíos regulatorios en un determinado proyecto de ley. Al respecto véase Zapata Larraín, cit. (n. 8), pp. 315316. 
de la constitución, la jurisprudencia inicial desarrollada por el Tribunal Constitucional ejerciendo la competencia del artículo $82 \mathrm{No}$ C.Pol. (numeración antigua) respecto de los decretos supremos que, adecuados a la ley, se estimaban no obstante contrarios a la Constitución ${ }^{15}$, tesis que la propia autora califica como la de vinculación directa del Presidente a la Constitución. Algunos autores y la disidencia al interior del propio Tribunal opinaban que éste no podía realizar dicho pronunciamiento en cuanto implicaba tácitamente considerar inconstitucional la ley que servía de sustento al decreto, consideración sobre la constitucionalidad de una ley vigente que la Constitución no entregaba al Tribunal, tesis denominada por Bulnes Aldunate como principio de jerarquía de las normas ${ }^{16}$.

b) Ocasionalmente, sin mención expresa, pero con claro sentido de "dar eficacia" o "aplicación" a las disposiciones constitucionales, el Tribunal Constitucional procede a ejercer sus atribuciones en una especial modalidad. Podría estudiarse como una variante de comprensión de la fuerza normativa de la Constitución los casos en que el Tribunal, sin tener atribuciones para ello, dicta sentencias exhortativas, o interpretativas ${ }^{17}$; cuando interpreta de forma amplia una atribución que le es conferida expresamente para extenderla a casos que parecen no estar comprendidos dentro de ella (rol No 591-06) o bien cuando, en ausencia del requisito de ley orgánica que la propia Constitución le impone para ejercer su competencia para declarar de oficio la inconstitucionalidad de la ley, el Tribunal pasa por alto este requisito (rol No 681-06). En este grupo constituye un hito especial, por sus consecuencias para el orden constitucional, la referencia al principio de inexcusabilidad en el marco de las decisiones del Tribunal (rol No 740-07, considerando 63º), que se discute más adelante. Muchos de estos casos pueden ser evaluados críticamente desde el punto de vista de un análisis detenido de lo que se entienda bajo la idea de fuerza normativa de la constitución y lo que se busque con ella, pero no cabe duda que ellos han tenido lugar en el contexto de determinadas concepciones o formas de comprensión, intuitivas o reflexivas, sinceras o a modo de pretexto, sobre dicha fuerza.

A continuación se examinarán algunos de los puntos de este inventario

${ }^{15}$ Bulnes Aldunate, cit. (n. 4), p. 141. La autora cita como ejemplos las sentencias recaídas en las causas roles $\mathrm{No}_{s}$ 116, 146, 153 y 167.

${ }^{16}$ Ibíd.

${ }^{17}$ Las sentencias interpretativas se relacionan con la idea interpretación conforme como expresión o consecuencia de la fuerza normativa de la constitución. Para el concepto y ejemplos de sentencias interpretativas y exhortativas, ZaPATA LARraín cit. (n. 8), pp. 326 ss. 
de contenidos o consecuencias que se predican como parte de la noción de fuerza normativa de la constitución.

III. PROBLEMAS DE LA DOCTRINA SOBRE FUERZA NORMATIVA DE LA CONSTITUCIÓN Y DE SU APLICACIÓN

Diferentes facetas de la doctrina de la fuerza normativa de la constitución presentan aspectos discutibles o requeridos de mayor análisis; en algunos casos, dicha doctrina de la fuerza normativa de la constitución, tal y como es entendida y aplicada a nivel jurisdiccional, ha llevado incluso a contradecir su sentido propio. Este acápite está dedicado al examen de dichos aspectos.

1. Fuerza normativa de la constitución, necesidad de complemento legislativo, facultades supletorias de la jurisdicción.

Como se ha señalado en el $\$ 2$, la afirmación de la eficacia directa de la constitución no implica sostener que ella no requiere de la intervención legislativa para desplegar sus plenos efectos: sólo significa decir que puede tener algún efecto aún sin dicha intervención. Es así como Fernández Gonzalez (2001) reconoce que si bien la Constitución contempla preceptos que no requieren de mediación normativa alguna, existen otros, usualmente vinculados con la parte orgánica de la Constitución, que sí precisan de esta mediación ${ }^{18}$. A partir de éstos se derivarían consecuencias diferenciadas. En el primer caso, cuando los preceptos constitucionales no requieren mediación normativa, ello conllevaría su obligatoriedad para todos, y un deber de directa aplicación para todos los órganos del Estado. En este caso, y ante la falta de otra regulación de forma o procedimientos para dar vigencia concreta al precepto constitucional, el respectivo órgano debiese recurrir a las normas del derecho común, o en último término, a los principios y reglas generales del derecho ${ }^{19}$. En cambio, cuando la Constitución requiere de mediación normativa, su fuerza normativa, esto es, su vinculatoriedad, se traduce en que los órganos competentes, en su caso los tribunales, deberán constatar el incumplimiento del deber por parte de quien tenía que complementar el precepto constitucional, activando mecanismos de responsabilidad política o constitucional (aun cuando sin poder de compulsión sobre el respectivo órgano remiso, para que cumpla su deber).

Esta segunda hipótesis aún admite una distinción adicional, ya que Fernández González señala que si de la omisión en complementar las disposiciones constitucionales se sigue una infracción a los derechos fun-

\footnotetext{
${ }^{18}$ FernÁNdeZ GonZÁLEZ, cit. (n. 7), p. 79.

${ }^{19}$ Ibíd., p. 79.
} 
damentales, el tribunal debe proceder a la aplicación directa e inmediata de la preceptiva constitucional. El problema de esta postura es que no queda claro cómo, en estos casos, el tribunal debe proceder a la integración de las fuentes para construir las reglas faltantes, las que no ha provisto el respectivo órgano. El autor enfatiza que esta actuación en suplencia del respectivo tribunal sólo procede ante lesión de derechos fundamentales ya que de lo contrario se correría en el riesgo anotado por Loewenstein, a quien cita, de caer en una judiciocracia. Sin embargo, no se aprecia por qué este peligro desaparecería si el tribunal se limita a suplir la ausencia de reglas en caso de lesiones a derechos fundamentales. La mayor parte de las veces son precisamente estos casos aquellos en torno a los cuales giran las controversias políticas más importantes y que más cuestionan la distribución de competencias en el estado de derecho ${ }^{20}$.

\section{El desdoblamiento de la fuerza normativa entre derogación y supre-} macía.

Un segundo problema que atañe al campo de la fuerza normativa de la constitución es la distinción que se realiza a su respecto en relación con las facultades de los jueces de la instancia al momento de enfrentar una antinomia entre Constitución y preceptos subconstitucionales, distinción que afirma que si el criterio a aplicar es exclusivamente el de supremacía, no está dentro de las facultades del juez pronunciarse resolviendo la antinomia y tiene como única vía para resolverla el recurrir vía artículo 93 inciso $11^{\circ}$ C.Pol. al Tribunal Constitucional, planteando la respectiva acción de inaplicabilidad. En cambio, si la antinomia puede ser resuelta como resultado de una derogación tácita del respectivo precepto legal por la sobreviniente promulgación y entrada en vigencia de la Constitución, entonces se reconoce al juez esta facultad ${ }^{21}$. No se observa una razón para

\footnotetext{
${ }^{20}$ Piénsese simplemente en los casos "Píldora I” y "Píldora II" (roles No 591-06 y No 740-07) en la reciente jurisprudencia de nuestro Tribunal Constitucional.

${ }^{21}$ En fallo de 26 de Noviembre de 2008, rol No 5420-08, la Corte Suprema, conociendo de un recurso de nulidad de juicio oral en lo penal, reafirmó este criterio en el considerando $4^{\circ}$ de la sentencia: "Que, antes de resolver el punto de derecho especifico promovido, es previo decidir acerca de la cuestionada competencia de los jueces del fondo para concluir la derogación tácita del artículo 450 inciso $1^{\circ}$ del Código Penal, al estimarlo contrario a los principios constitucionales./ Para esta Corte, en términos generales, incumbe a todo Juez de la República la aplicación del ordenamiento jurídico a los casos concretos sometidos a su decisión./ La integralidad y coherencia de dicho sistema de normas obliga al juzgador a elegir la norma o grupo de normas precisas que utilizará y el sentido de las mismas. En el ejercicio de esa labor intelectual de selección e interpretación puede identificar reglas juridicas que contienen sentidos opuestos, e incluso reglas jurídicas que se oponen a sendos principios rectores del sistema jurídico. Pues bien, la
} 
afirmar que el mismo juez que puede resolver la antinomia en el caso de derogación tácita no puede realizar la misma operación cuando la misma antinomia opera respecto de la misma Constitución, sólo que respecto de un precepto posterior a la entrada en vigencia de la misma. El argumento que señala que ello se debe al sistema de concentración de control de constitucionalidad en el Tribunal Constitucional pasa por alto que esta magistratura no resuelve, para la respectiva gestión judicial, la antinomia entre Constitución y precepto legal, sino que la elimina, al retirar del universo de fuentes que deberá considerar el juez del fondo, al resolver, el precepto legal cuya aplicación se impugna por inconstitucional. De este modo no se le ha otorgado al Tribunal Constitucional la facultad de resolver estas antinomias y mal podría sostenerse entonces que a los jueces del fondo carecen de una atribución, porque ésta se alega entregada al Tribunal, cuando efectivamente no se le ha entregado. Esta solución es precisamente el argumento que tiende a reforzar la idea de que el predicado de fuerza normativa de la constitución como eficacia directa incluye al derecho constitucional en el sistema de fuentes que debe considerar y resolver cualquier juez, de acuerdo a la idea de control difuso examinada arriba.

\section{La invocación de la eficacia directa de la Constitución como elemento} atentatorio contra la fuerza normativa de la Constitución

Uno de los mayores problemas de la invocación de la fuerza normativa de la constitución entendida como eficacia directa, es que, curiosamente, puede producir efectos justamente contrarios a los que se persigue con esta idea, a saber, el despliegue de la normatividad de la Constitución en cuanto fuente del derecho. Este fenómeno se ha venido incrementando en el manejo del texto constitucional por parte del Tribunal Constitucional a

solución de tales conflictos de normas es también objeto del juzgamiento./ No se discute, en la doctrina constitucional, que los jueces del fondo tengan facultades para interpretar las reglas legales conforme a la Constitución, asi como tampoco la utilización de las normas constitucionales de un modo directo para la solución del conflicto especifico y, en ambos casos, el juez ha debido interpretar la Constitución./ Del mismo modo, es de competencia de los jueces del fondo el determinar la vigencia de una regla jurídica, ante la existencia de normas posteriores de contenido opuesto, sea que esa norma posterior tenga rango legal o constitucional. No altera el aserto precedente la modificación de nuestra Carta Fundamental, efectuada con ocasión de la Ley $N^{\circ} 20.050$ de 25 de agosto de 2005. En efecto, el inciso undécimo del artículo 93 de la Constitución Política de la República no prohibe una actuación de esa indole y sólo contiene una facultad para el juez que conoce del asunto, en el sentido de elevar la consulta al Tribunal Constitucional, en caso de duda relativa a la inaplicabilidad de un precepto legal cuya aplicación resulte contraria a la Constitución [...]". 
partir de la reforma del año 2005, y puede mostrarse a la luz de diferentes manifestaciones.

a) La primera se da cuando, bajo el pretexto de aplicación de la Constitución, se incorporan elementos normativos del todo ausentes en ella. Este el caso con la invocación del estado social en el fallo rol No 976-07. Es indiscutible que en aquellos textos constitucionales que contemplan una cláusula de estado social de derecho o estado social y democrático de derecho, ella constituye un punto de partida para la respectiva construcción normativa. Sin embargo, en nuestra Carta no es ese el caso. La conclusión a la que pudiese llegarse sobre la consagración o no de un determinado modelo ${ }^{22}$, podrá ser de naturaleza doctrinaria, pero no puede situarse en el mismo plano que los datos contenidos en el texto de la Constitución. Sin embargo, en el fallo en comento, el Tribunal Constitucional introduce una argumentación sobre la base del estado social como si se tratase de un argumento derivado de la propia Constitución, al menos suficiente para construir una afirmación respecto de los derechos sociales en el c. 29\%: "Que el derecho a la protección de la salud es de indole social, involucrando conductas activas de los órganos estatales y de los particulares para materializarlo en la práctica, habida consideración que la satisfacción de tal exigencia representa un rasgo distintivo de la legitimidad sustantiva del Estado Social en la democracia constitucional contemporánea".

La pregunta que surge es si, por mucho que determinados estándares y elementos del credo de legitimidad sean compartidos por la doctrina y eventualmente la comunidad occidental, ellos pueden ser asimilados a los que encuentran su recepción positiva en el texto constitucional, o si más bien es necesario distinguirlos y separarlos para evitar, justamente, que la fuerza normativa de la constitución se disuelva en fuentes no positivas como podrían ser, parafraseando la filosofía aristotélica, "las convicciones de la comunidad de personas decentes y bien intencionadas de occidente".

b) La segunda manifestación de este efecto contraproducente o contranormativo está dada por un manejo laxo y relajado de la invocación, junto con la idea de una constitución normativa, la de una constitución continente de valores y principios ${ }^{23}$, los que se estiman especialmente pre-

${ }^{22}$ Que, si se colaciona toda la doctrina nacional, vendría siendo una verdadera Quimera constitucional con cabeza de modelo neoliberal, cuerpo de estado subsidiario y cola de estado social de derecho, modelos incompatibles entre sí, y mucho más reunidos.

${ }^{23}$ Cabe aquí hacer una precisión similar a la idea expresada respecto del empleo del término "estado social". Hay constituciones que, como la española, hacen referencia expresa a valores y por lo tanto la discusión sobre los valores constitucionales está incluida dentro de los problemas de su fuerza normativa. Cuando la constitu- 
sentes en los preceptos constitucionales sobre derechos fundamentales. Este tópico abarca una serie de problemas, pero en lo que aquí interesa puede resumirse diciendo que, considerada la constitución como continente de valores y principios, queda entregada al intérprete constitucional, a través de un procedimiento de ponderación, la determinación de las soluciones concretas que se pueda dar a las eventuales colisiones entre dichos principios y valores. Nuestro Tribunal Constitucional, en diferentes fallos, pero de manera particularmente enfática en el ya mencionado rol No 976-07, estima comprendidos dentro de la supremacía constitucional no sólo las normas que puedan derivarse de la Constitución, sino también los "valores" y "principios" articulados en ella: considerando 25: "Que, con sujeción al artículo $6^{\circ}$, inciso segundo, de la Constitución, todos los valores, principios y normas articulados en ella gozan de la supremacía que caracteriza a tal ordenamiento jurídico-politico, rasgo del cual se sigue que ningún órgano estatal, persona, institución o grupo puede válidamente invocar otras disposiciones de ese texto, ni acudir a su contexto o espiritu para prescindir de tan importante obligación, reputarse eximido de acatarla o dejar de asumir los deberes inherentes a dicha supremacía".

El problema que trae aparejada esta invocación a valores y principios es que permite al juzgador constitucional resolver el caso sobre una argumentación ponderativa cuyo efecto es, precisamente, la imposibilidad de fundar en el texto constitucional el criterio utilizado para darle solución . Si se toman como base los respectivos preceptos sobre libertad de opinar e informar y protección de la honra del artículo 19 No 12 inciso $1^{\circ}$ y No 5 , y se llevan a un caso de colisión, la referencia al texto constitucional se agota en la construcción de la colisión a partir de ellos. La solución que se dé a esa colisión por la vía de ponderación, empero, no puede ser vinculada a texto constitucional alguno ${ }^{24}$. Constatada entonces la existencia de resolución de controversias constitucionales al margen del texto constitucional es forzoso concluir la pérdida de la fuerza normativa del mismo.

Más evidente resulta el vaciamiento de la fuerza normativa de la Constitución producto de la invocación de valores o principios cuando ella permite un salto, sin conexión argumental, entre la invocación a dichos valores y la garantía constitucional al contenido esencial prevista

ción no destaca valores en cuanto tales, pero se da a determinados preceptos constitucionales esta calidad, es cuando se plantea el problema que aquí se discute.

${ }^{24}$ Para una demostración de esto a la luz de tres casos de la jurisprudencia alemana citados como ejemplares por el propio Alexy, véase: García Amado, Juan Antonio, El juicio de ponderación y sus partes. Una crítica, en Alexy, Robert, Derechos sociales y ponderación (Madrid, Fundación Coloquio Jurídico Europeo, 2007), pp. 249-331. 
en el artículo 19 No 26, como sucede en el rol No 943-07. Considerando 30": "Que, como ya se ha señalado, el contenido del artículo 19 de la Carta Fundamental, conjuntamente con sus articulos $1^{\circ}, 4^{\circ}$ y $5^{\circ}$, inciso segundo, de la misma, configuran principios y valores básicos de fuerza obligatoria que impregnan toda la Constitución de una finalidad humanista que se irradia en la primacía que asignan sus disposiciones a la persona humana, a su dignidad y libertad natural, en el respeto, promoción y protección a los derechos esenciales que emanan de la naturaleza humana, que se imponen como limitación del ejercicio de la soberanía y como deber de los órganos del Estado". Considerando 310: "Que estos principios y valores, como ya se recordó -y lo hace manifiesto el inciso segundo del artículo $\sigma^{\circ}$ de la Constitución, que precisa que sus preceptos obligan no sólo a los titulares o integrantes de los órganos del Estado sino a toda persona, institución o grupo-, no configuran meras declaraciones programáticas sino que constituyen mandatos expresos para gobernantes $y$ gobernados, debiendo presidir la labor del intérprete constitucional, en cuanto normas rectoras y vitales que coadyuvan a desentrañar el verdadero sentido y espiritu del resto de las disposiciones de la Constitución”.

Considerando 32०: "Que, por lo recién expresado, debe desecharse toda interpretación de las normas constitucionales que resulte contradictoria con los aludidos principios y valores rectores de la Carta Suprema. Ello lleva a concluir que, frente a las interpretaciones posibles del alcance de la protección constitucional de un derecho fundamental, deba desecharse la que admita que el legislador pudo regular sus efectos hasta extremos que, en la práctica, imposibilitan la plenitud de su vigencia o comprimen su contenido a términos inconciliables con su fisonomía./ En efecto, el legislador no es libre para regular el alcance de los derechos fundamentales que la Constitución reconoce y asegura a todas las personas. Por el contrario, y como lo dispone el artículo 19, No 26, de la misma, debe respetar la esencia del derecho de que se trata como también evitar la imposición de condiciones, tributos o requisitos que impidan su libre ejercicio. En este sentido, esta Magistratura ha considerado, precisamente, que un derecho es afectado en su "esencia" cuando se le priva de aquello que es consustancial de manera tal que deja de ser reconocible (sentencia rol $N^{\circ} 43$, de 24 de febrero de 1987, considerando 210)".

c) En tercer lugar, se da un debilitamiento de la fuerza normativa de la constitución cuando, alegando la necesidad de actuar dando eficacia a la Constitución, se pasa por encima de su texto, como fue el caso en el rol No 681-06. La Constitución prescribe que la declaración de oficio de inconstitucionalidad se regirá por lo dispuesto en la respectiva ley orgánica constitucional. Literalmente señala la carta en su artículo 93 inciso 120: "Corresponderá a la ley orgánica constitucional respectiva establecer los requisitos de admisibilidad, en el caso de que se ejerza la acción pública, 
como asimismo regular el procedimiento que deberá seguirse para actuar de oficio". Si los órganos públicos sólo pueden actuar previa investidura, dentro de su competencia y en la forma prescrita por la ley, no basta la mera consagración de la competencia de un órgano para que se encuentre habilitado para actuar; en especial si la habilitación es imperativa (" $e l$ procedimiento que deberá seguirse"). Sin embargo, en el rol No 681-06 el Tribunal Constitucional se entendió habilitado para pasar por sobre esta exigencia constitucional y ejercer la acción de inconstitucionalidad de oficio, sin regulación legal orgánica constitucional.

d) Un resultado similar resulta del manejo de la constitución homologado al de la ley escrita en el ámbito del derecho privado, respecto de la cual se predica el principio de inexcusabilidad. El deber de fallar aún a falta de ley escrita que resuelva el conflicto conlleva la habilitación, para el órgano jurisdiccional, para elaborar la regla decisoria tal y como podría haberlo hecho el legislador. Aplicado al nivel constitucional, el principio de inexcusabilidad al que se alude en la ley orgánica del Tribunal Constitucional y al que se hace referencia en algunos fallos de este órgano implicaría que, a falta de disposición expresa, el juez constitucional debe elaborar la regla decisoria tal y como podría haberlo hecho el constituyente. Esto implica desconocer que la constitución no sólo se define en torno a lo que regula, sino especialmente en torno a aquello que no regula y que por tanto queda entregado a la libre decisión del legislador. Aceptar la idea de un principio de inexcusabilidad bajo el pretexto de eficacia directa o fuerza normativa de la constitución implica que esta fuerza se desplaza, del texto constitucional, a la decisión de los jueces constitucionales. Queda por ver si queremos llamar también a esto, en términos doctrinario jurídicos, o incluso políticos, fuerza normativa de la constitución.

e) Por último, debe señalarse que la discusión sobre el posible rango constitucional de los tratados internacionales, o la doctrina del bloque de constitucionalidad configurado por normas construidas sobre una base de textos normativos más amplia que el texto de la constitución implica, respecto de éste, una disminución de su índice de relevancia -y por lo tanto de fuerza normativa- en el correspondiente proceso de construcción normativa ${ }^{25}$. Utilizando una metáfora, la idea de bloque de constitucionalidad tiende a diluir la enjundia constitucional en un caldo mucho muy aguado

${ }^{25}$ Aros Chia, cit. (n. 11), p. 147, pregunta en un párrafo de su trabajo "Cómo llevo a la práctica la Fuerza Normativa [sic] de la constitución y el bloque de constitucionalidad"? a lo que cabría responder con una pregunta anterior: ¿cómo es que el tópico de la fuerza normativa de la constitución se extiende de pronto -y sin explicación- al análisis de la fuerza normativa de la constitución y de los demás elementos que forman partes del 'bloque de constitucionalidad'? 
de textos no constitucionales. Puede aceptarse o no esta doctrina; pero, si se acepta, parece inconcuso que no se puede desconocer esta disminución, en términos comparativos, de la participación del texto constitucional en el resultado final de la construcción normativa.

4. La fuerza normativa y la distribución de competencias en materia de amparo o tutela extraordinaria de derechos fundamentales.

La noción de fuerza normativa de la constitución, en cuanto postula su eficacia directa, se ha visto reforzada en una primera apreciación, por una serie de disposiciones legislativas que amplían las competencias señaladas por la Constitución que permiten a un tribunal operar sobre la directa invocación de preceptos constitucionales en la construcción de la norma decisoria litis. Ello se ha dado, hasta ahora, por la inclusión de acciones o recursos procesales específicos vinculados a la afectación de derechos fundamentales, como sucede en el caso de la acción de amparo económico, del recurso de nulidad en materia penal y en materia laboral (en este último caso consagrado bajo el nombre de apelación, cfr. artículo 477 del Código del Trabajo), de la tutela laboral (artículo 485 ss. Código del Trabajo) y más recientemente la acción especial de reclamo por vulneración de derechos ante la jurisdicción aduanera y tributaria (artículo $129 \mathrm{~K}$ de la ley No 20.322). Se dice que podría estimarse reforzada en una primera apreciación por el hecho de que, en todos estos casos, el legislador genera una habilitación específica para situar a los respectivos preceptos constitucionales (sobre garantías constitucionales o derechos fundamentales) en la base de la decisión jurisdiccional, como derecho directa -y en muchos casos, exclusivamente- aplicable a la resolución del caso. Sin embargo, en una reflexión ulterior se constata que esta práctica legislativa de distribución de competencias de aquello que, en sentido amplio, se ha venido a denominar el amparo o tutela extraordinaria de los derechos fundamentales conlleva un riesgo para la fuerza normativa de la Constitución. En efecto, cuando se instala este tópico en la discusión, ocasionalmente se olvida que no se trata simplemente de afirmar la fuerza normativa de la Constitución en cuanto texto normativo (que es un problema que se discutirá más abajo), sino que en cuanto constitución. Esta afirmación, que no parece agregar nada a la idea de normatividad del texto constitucional, tiene sin embargo un sentido relevante en el plano constitucional. Si la constitución es el ordenamiento jurídico político fundamental en un país, su fuerza normativa sólo puede entenderse con carácter unitario. A diferencia de lo que puede suceder con otros textos normativos que no cumplen esta función basilar, no tendría sentido que el diseño de aplicación de la constitución permitiese que su carácter unitario fuese puesto en entredicho. Pero resulta que el carácter unitario de la constitución no es un dato dado simplemente por 
la existencia de un único texto constitucional, sino por el manejo que del mismo se haga. Y en este sentido la unidad de la constitución significa que no es admisible, para el sistema institucional, la coexistencia de afirmaciones paralelas, divergentes o claramente incompatibles, sobre el sentido atribuido al texto constitucional. La distribución de competencias para activar la normatividad del texto constitucional en diversas instancias ${ }^{26}$ permite, sin embargo, el surgimiento de estas afirmaciones, que debilitan la unidad de la Constitución y en esta medida, su fuerza normativa.

\section{LA FUERZA NORMATIVA DE LA CONSTITUCIÓN COMO TÓPICO DE LA TEORÍA DE LA CONSTITUCIÓN. SU APLICACIÓN AL SISTEMA DE FUENTES}

Respecto de origen del tópico relativo a la fuerza normativa de la constitución es importante anotar que con esta idea, en sus inicio no se alude tanto a la consideración de la aplicación de la constitución como norma vinculante-cuestión que, si se quiere, parece darse por supuesta- sino más bien a una pregunta clave de la ciencia del derecho constitucional. Conocida es la referencia a la conferencia pronunciada por Lasalle el 16 de abril de 1862, en que sostenía que la constitución escrita es sólo un trozo de papel, mientras que lo que determina realmente las cuestiones constitucionales son las relaciones efectivas de poder: poder militar (el ejército) poder social (los terratenientes); poder económico (la gran industria y el gran capital), y, aunque no equiparable a los anteriores, el poder espiritual. A partir de ésta, la constitución real de un país, surge entonces la pregunta relativa a en qué medida es posible que los instrumentos o cartas constitucionales lleguen a ser un efectivo factor para regular la constitución del país, o sea, para que frente a dichos poderes la constitución escrita pueda llegar a desplegar una fuerza normativa, tomando en cuenta en especial la idea de que las fuerzas políticas reales se mueven según sus propias leyes, con independencia de cualesquiera formas jurídicas ${ }^{27}$. "La cuestión, de este modo planteada -dice Hesse- es la de la fuerza normativa de la constitución ¿Existe, junto a la fuerza determinante de las relaciones efectivas, de las fuerzas sociales y políticas, una fuerza determinante del Derecho constitucional? ¿En qué se

${ }^{26}$ Anuncia ya este tema Bordalí Salamanca, Andrés, La unidad en la interpretación jurisdiccional de los derechos fundamentales: una tarea pendiente en el Derecho chileno, en Revista Chilena de Derecho 34 (Pontificia Universidad Católica de Chile, septiembre - diciembre de 2007), pp. 517-538.

${ }^{27}$ JellineK, Georg, Verfassungsänderung und Verfassungswandlung (1906), p. 72, cit. en Hesse, Konrad, La fuerza normativa de la Constitución, en Hesse, Konrad Escritos de Derechos Constitucional (2a edición, Madrid, Centro de Estudios Constitucionales, 1992), p. 58. 
apoya esta fuerza y hasta donde alcanza? [...]. Estas cuestiones surgen muy especialmente en el ámbito de la constitución porque aquí, a diferencia de otros sectores del ordenamiento jurídico, falta en último término la garantía exterior de la imposición de los mandatos jurídicos". El problema específico de la fuerza normativa de la constitución deviene entonces en la cuestión de cómo ella misma y su aplicación inciden en las condiciones necesarias para que tenga alguna función orientadora del comportamiento en el sistema político, distinta a la que podría resultar del simple juego de los factores de poder presentes en ese sistema. Para ello según Hesse, se requiere de dos factores. La constitución debe dar cuenta, al menos en alguna medida, de las relaciones de poder existentes, debe reposar en una adaptación inteligente a las circunstancias, en vistas a la tarea regulatoria que plantea. Para lograr eso, la propia constitución debe transformarse en una fuerza actuante, para lo cual debe existir una "voluntad de constitución" ("Wille zur Verfassung"). Señala Hesse que "la fuerza que yace en la naturaleza de las cosas, que le lleva a actuar y orientar su actividad y ser además ella misma fuerza actuante, en eso consiste la naturaleza y la eficacia de la fuerza normativa de la constitución"28.

La relevancia de volver sobre el sentido original de la fuerza normativa de la constitución está dada porque ella dice directa relación con la extensión que pueda predicarse de dicha fuerza normativa en términos de su contenido, o sea, en términos de lo que se puede y es conveniente esperar que la constitución regule. Es justamente a fin de que la constitución pueda desplegar la fuerza normativa entendida como la plantea Hesse que deben tenerse en consideración ciertos aspectos que podrían denominarse "técnicos" del diseño constitucional. Es así como Hesse, afirma que cuanto más consigue una constitución, en base a su contenido, corresponder a la disposición del presente, con mayor seguridad podrá desarrollar su fuerza normativa ${ }^{29}$. Para ello, junto a la adecuación a las circunstancias del presente "es esencial que la constitución pueda adaptarse a un cambio de circunstancias". Para ello, la constitución debe limitarse, en la medida de lo posible, a unos pocos principios elementales (que luego puedan ir siendo detallados a nivel no constitucional). Si en la constitución se anclan,

${ }^{28}$ Hesse, cit. (n. 27), p. 67.

${ }^{29}$ La referencia ocasional a esta consecuencia (por ejemplo en Aros CHIA, cit. (n. 11), pp. 146, 147, con una remisión a un trabajo de Raúl Gustavo Ferreira que no hace sino reproducir esta idea de Hesse, casi 50 años más tarde) dentro de la misma categoría conceptual de la eficacia directa o supremacía jerárquica muestra cómo la falta de claridad conceptual induce a velar, o al menos desplazar a un segundo plazo, la necesidad de reflexionar sobre las condiciones necesarias para que la constitución despliegue una fuerza reguladora. 
por el contrario, intereses particulares o coyunturales, se hacen "inevitables las modificaciones frecuentes de la constitución, con la consiguiente depreciación de su fuerza normativa" 30 También es posible prever esta depreciación a partir de la inclusión de preceptos constitucionales con una finalidad meramente simbólica, o sin expectativa de concreción efectiva en el ordenamiento jurídico subconstitucional; casos en los cuales puede decirse que la "promesa normativa" de la constitución queda incumplida.. De este modo, la idea de buscar la mayor fuerza normativa de la constitución debiese llevar a una reflexión tanto sobre la conveniencia de la frecuente modificación a la carta (que debilita la voluntad a la constitución como un acuerdo fundamental) como sobre la tendencia a querer ver en la constitución la fuente para la resolución de todo tipo de conflictos (en especial a través del postulado del efecto horizontal de los derechos fundamentales) o el depositorio de toda declaración sobre aquello que pueda estimarse valioso o digno de reconocimiento.

Como puede apreciarse, el sentido original del tópico de la fuerza normativa de la constitución lleva consigo a una contención, y no a una ampliación de los contenidos normativos a los que se pueda aspirar por vía de las construcciones teóricas o interpretativas del texto constitucional. Por otro lado, se destaca en esta visión la necesidad de apreciar de manera crítica el grado en que la Constitución efectivamente despliega su fuerza normativa en el sistema político y jurídico. Así por ejemplo, hay una serie de casos en que se puede plantear una duda sobre el grado de normatividad que alcanzan determinados preceptos (el deber de asegurar el derecho de las personas a participar en la vida nacional con igualdad de oportunidad del artículo $1^{\circ}$ inciso $1^{\circ}$, el derecho a la justa retribución del artículo 19 No 16 inciso $2^{\circ}$, por ejemplo); en otros, no cabe duda de que dicha normatividad tiende a cero, como en el caso del artículo 19 No 16 inciso final, bajo la figura de los "paros" (no "huelgas") de funcionarios del Estado o de personas que trabajan, por ejemplo, en el sistema de transporte público. El poder de los respectivos gremios hace que, en el caso del sector público, y ocasionalmente, se llegue a premiar en los hechos la paralización, con un "bono de término de conflicto". Tras estas prácticas se pasea el fantasma muy real de Lasalle. Sin embargo, no es sólo en este ámbito donde se da una pérdida de la fuerza normativa de la Constitución; en el caso chileno, ella adquiere particular relevancia en el ámbito del sistema de fuentes. Aquí se constata que nuestra praxis institucional se aparta de 1) la sistemática construcción de la distribución de potestades normativas en la Constitu-

\footnotetext{
${ }^{30}$ Hesse cit. (n. 27), p. 67.
} 
ción; 2) de determinados conceptos constitucionales, y 3) de la extensión normativa que se puede predicar de las disposiciones constitucionales.

\section{Fuerza normativa de la Constitución y alteración del régimen consti-} tucional de potestades normativas.

En una primera dimensión del análisis, si se analiza la regulación constitucional y luego se observa la realidad de la praxis legislativa y jurisprudencial en esta materia se aprecian importantes discordancias, lo que es decir que en este ámbito la Constitución no despliega una efectiva fuerza normativa frente a otros elementos condicionantes, como puede ser, por ejemplo, la consideración de datos tradicionales o de eficiencia al momento de asumir el costo de una pérdida de dicha fuerza.

Nuestra Constitución contiene en los artículos 32 No 6 y 63 una distribución de competencias que, en materia de creación de textos normativos, aparece como cerrada. A la ley corresponde regular las materias señaladas en el artículo $63 \mathrm{No}^{\circ} 1$ a 19 , y, en términos de intensidad regulatoria, toda otra materia con tal de que acometa dicha regulación estableciendo las bases esenciales de un ordenamiento jurídico (artículo 63 No 20). El remanente es entregado al Presidente de la República en el artículo 32 No 6, en la calidad de jefe de gobierno y de la administración del Estado que le atribuye el artículo 24. Las fuentes constitucionales acotan esta distribución competencial con preceptos que contemplan, ya sea de manera expresa una facultad de dictar reglamentos (facultad de las cámaras para dictar sus reglamentos, artículo 56, misma facultad del Consejo de Seguridad Nacional, artículo 107), ya sea una habilitación para participar en la creación de textos normativos, como en el caso del Banco Central (inciso final del artículo 109: "acuerdos [...] que signifiquen [...] establecer normas") de los consejos regionales ("órgano de carácter normativo" artículo 113), y los concejos comunales (“funciones normativas", artículo 119), y, tras la reforma del año 2005, la facultad de dictar autos acordados de las cortes de apelaciones, la Corte Suprema y el Tribunal Calificador de Elecciones (artículo 93 inciso $1^{\circ}$ No 2$)^{31}$. Puede discutirse el contenido específico respecto del cual, en cada uno de estos casos, se produce una atribución de competencias normativas en detrimento de la potestad reglamentaria presidencial; pero en todos estos casos ella tiene sustento constitucional. La conclusión que resulta del análisis de estas disposiciones es que, salvo en el caso de desarrollar las disposiciones que modulan la competencia residual de la potestad reglamentaria del Presidente de la República, la ley

${ }^{31}$ Lo relevante no es la mera consagración constitucional del órgano, sino que la habilitación constitucional de una potestad regulatoria. 
no puede otorgar competencias regulatorias a órganos que quedan fuera del campo de acción jurídica del Presidente. De este modo, las leyes que otorgan facultades regulatorias a entes que no cuentan con habilitación constitucional de potestad normativa, y que presentan autonomía jurídica respecto del Presidente de la República, alteran facultades constitucionalmente entregadas al PdlR y son, en consecuencia, inconstitucionales. Sin embargo, en la medida en que se han dictado y siguen dictándose, y no existe a su respecto un sustancial reproche de constitucionalidad (en términos de atribución de competencia, y no de sus posibles contenidos) es posible evaluar esto como un caso en que la Constitución, respecto del sistema de fuentes, no despliega fuerza normativa; el modelo normativo de distribución de competencias regulatorias ha sido alterado permitiendo que sea intervenido por la ley, la que ha otorgado a diversos órganos administrativos facultades reguladoras, sin sustento constitucional. Esto puede darse de tres maneras.

Hay casos en que, dentro de la estructura jerárquica de gobierno y administración, se crean instancias o procedimientos que sustraen del ámbito de acción del Presidente de la República algunos aspectos del ejercicio de la potestad reglamentaria, de tal modo que el poder de decisión queda radicado en un órgano exento de su potestad de instrucción. Esto sucede en el caso de la legislación pesquera, donde, si bien es cierto la forma de algunas decisiones sigue siendo la de decreto supremo, o resolución, su contenido es aportado por una decisión del Consejo Nacional de Pesca misma que no puede ser determinada -ni enervada- por la autoridad ejecutiva.

Se encuentran también órganos que sólo aparecen vinculados al PdlR por la posibilidad de remover al titular del respectivo órgano. Un ejemplo lo encontramos en el caso del director del Servicio Nacional de Aduanas, dentro de cuyas facultades se contemplan varias de naturaleza normativa y que pueden considerarse de carácter reglamentario: fijar y modificar la organización interna de las unidades del servicio, interpretar administrativamente disposiciones legales y reglamentarias, dictar normas de régimen interno, dictar normas para el cumplimiento de la legislación y reglamentación aduanera, dictar resoluciones generales en materia de personal $^{32}$. Cosa similar ocurre con las superintendencias ${ }^{33}$. En estos casos el Presidente sólo puede confiar en la expectativa de cumplimiento de sus directrices, a través de la presión que ejerce la posibilidad de remoción, pero no tiene potestad de instrucción sobre el respectivo órgano.

${ }^{32}$ Artículo 4 del DFL. No 329, de 1979, en diversos numerales.

${ }^{33}$ Cfr. la Ley de la Superintendencia de Valores y Seguros, DL. No 3.538, artículo 4, letras a), e), i) ñ), u); la Ley No 18.933: sobre Instituciones de Salud Previsional, artículo $3 \mathrm{No}_{\mathrm{s}} 2,7,8,9,9$ bis, 10, 13 . 
Por último hay casos en que se otorgan potestades reglamentarias a órganos propiamente autónomos. Así por ejemplo la Ley Orgánica Constitucional sobre Inscripciones Electorales y Servicio Electoral otorga al director de éste, en su calidad de jefe del servicio electoral, la facultad de "dictar resoluciones generales [...] necesarias para el ejercicio de sus atribuciones" (artículo 93, letra i) así como la de "dar instrucciones generales sobre la aplicación de las normas electorales" para su ejecución por los organismos establecidos en ellas" (artículo 93 letra k). Tanto en este caso, de los órganos propiamente autónomos, como en el de aquellos respecto de los cuales el Presidente no cuenta con poder de instrucción, las respectivas potestades normativas se encuentran jurídicamente desconsolidadas de la potestad reglamentaria del artículo 32 No 6 y son, en consecuencia, una práctica institucional contraria a la distribución constitucional de potestades normativas.

Otro tanto ocurre en el ámbito de las facultades de los tribunales productoras de los autos acordados. Su naturaleza es de claro carácter reglamentario $^{34}$. La evolución en esta materia, anterior a la reforma constitucional del año 2005, difiere en sus supuestos de aquellos que presenta actual texto constitucional. Mientras que el único sustento positivo de las facultades de la Corte Suprema, hasta antes de dicha reforma, era el artículo 79 (hoy artículo 82) de la Carta, que consagraba la superintendencia de la Corte Suprema, la reforma incluye una referencia expresa a los autos acordados emanados de la propia Corte, de las cortes de apelaciones y del Tribunal Calificador de Elecciones. El panorama, entonces, cambia, ya que la propia Constitución valida la producción normativa de los autos acordados a nivel de estos tribunales. El Tribunal Constitucional toma nota de este matiz en su sentencia recaída en rol No 783-07 cuando señala que: "Si el artículo 93 No 2 [sic] de la Carta Fundamental otorga a esta Magistratura competencia para revisar la constitucionalidad de estas normas, es evidente que valida esta competencia" (considerando 24\%). Sin embargo, al analizar la fuente de la facultad para dictar autos acordados, el Tribunal Constitucional señala que "desde siempre" se ha entendido que la capacidad para dictar autos acordados proviene de las facultades económicas que competen, en primer lugar, a la Corte Suprema, aunque también a las cortes de apelaciones. De este modo, el Tribunal parece aceptar, en contra del diseńo constitucional del sistema de fuentes en la distribución de competencias reguladoras, la introducción de una nueva fuente del Derecho, la "práctica inmemorial"

${ }^{34}$ Así, ya a principios de la década de 1970, Weinstein, Graciela, La naturaleza jurídica del auto acordado, en Revista de Derecho Procesal 1 (Universidad de Chile, 1971), pp. 5-34. La autora funda la potestad para dictar estos preceptos en la autonomía funcional que nace de la calidad de poder público que tiene el Poder Judicial. 
o tradición como fuente de Derecho público en Chile. En el considerando $24^{\circ}$ prosigue el tribunal: "El reducido ámbito regulatorio que la requirente pretende asignarle a los autos acordados no se aviene con la tradición de las importantes cuestiones que, desde la época de la Colonia, la Real Audiencia primero y luego la Corte Suprema vienen regulando por medio de autos acordados" ${ }^{35}$.

Sin embargo, esto sólo plantea una cara del problema, a saber, la fuente de la potestad regulatoria de los autos acordados. Pero tanto antes como después de la reforma del año 2005 queda abierta la cuestión relativa a la extensión de la respectiva potestad normativa. Al respecto, Francisco Zúñiga escribe: "[...] los autos acordados dictados por la Corte Suprema [...] no pueden insertarse en el ordenamiento jurídico como fuente formal a partir del principio de competencia, ya que la citada potestad no tiene contenidos normativos predeterminados por la Constitución. Esto significa que los autos acordados (juridicos y administrativos), es decir, referidos a la ley procesal o al servicio judicial, deben subordinarse a la ley, y al sistema de reparto de potestades normativas diseñadas en la Constitución" ${ }^{36}$. El problema que planteaba esta postura, antes de la reforma del año 2005, es que, si los autos acordados debían arreglarse al sistema de reparto de potestades normativas diseñadas en la Constitución, quedaban fuera: lo que no corresponde regular a la ley, es materia de potestad reglamentaria salvo las habilitaciones de potestades normativas expresas dentro de las cuales no se encontraban, a la sazón, los autos acordados. Tras la reforma del año 2005, la facultad para dictarlos no puede ser discutida, pero se mantiene la pregunta sobre su ámbito regulatorio que, siguiendo la situación de los demás órganos constitucionales con habilitación constitucional normativa distinta a la autoregulatoria o interna, debería ser definido por ley.

Esta cuestión también es abordada por el fallo del Tribunal Constitucional en la causa rol No 783-07. El Tribunal intenta un primer criterio basado en la independencia del Poder Judicial (considerando 25\%). Pero lo relevante para este trabajo es la solución final por la cual se inclina, ya que parece inaugurar un nuevo principio o criterio para la ordenación del sistema de fuentes en la Constitución, y la forma en que éstas operan. Se trata de un criterio de habilitación subsidiaria para el ejercicio de competencias regulatorias: existirían materias que no se encuentran asignadas estrictamente al ámbito legal, sino que en razón de un criterio de prevención, de tal modo que, mientras no han sido reguladas por el Legislador, cabría a los

${ }^{35}$ El destacado es mío [E.A.L.].

${ }^{36}$ Zúñiga Urbina, Francisco, Corte Suprema y sus competencias. Notas acerca de su potestad normativa (Autos Acordados), en Ius et Praxis 4 (Universidad de Talca, 1998) 1, p. 231. 
tribunales ordenarlas mediante un auto acordado. Si bien el fallo señala en su considerando $25^{\circ}$ que los autos acordados no pueden regular materias que el constituyente ha reservado al legislador, en el mismo considerando 25, la sentencia reza como sigue: "En aspectos de funcionamiento en que el legislador no ha establecido normas o que expresamente la Constitución no la ha reservado a éste, el propio órgano judicial puede auto regularse".

2) Debilitamiento de la fuerza normativa producto del método de construcción de conceptos y estándares normativos

Otra hipótesis en que la fuerza normativa de la Constitución se ve afectada se da en aquellos casos en que el correspondiente concepto o estándar constitucional que se trata de fijar no es construido a partir de la Constitución misma, sino que a partir de fuentes subconstitucionales, lo que dicho de otra manera podría expresarse como interpretación de la Constitución conforme a la ley. Cuando esto se produce en instancias decisorias de la jurisdicción constitucional, resulta claro que no es la Constitución la que despliega su fuerza normativa, sino que, a la inversa, ella se ve alimentada del contenido obtenido a partir de otras fuentes (que deberían entenderse subordinadas a la Constitución, y no supraordinadas en cuanto base de la respectiva construcción del contenido de los estándares constitucionales. En el fallo rol No 245-246, Playas Públicas I, el Tribunal Constitucional examina la cuestión planteada a partir de un examen de la regulación del deber de indemnizar limitaciones o restricciones al dominio a nivel legal. Cosa similar ocurre en el fallo rol No 943-07, donde las afirmaciones relativas a la extensión del deber de indemnizar a partir de hechos ilícitos se fundan exclusivamente en fuentes de tipo legal, sin lograr vincularse con una argumentación autónoma a nivel constitucional (lo que era por demás difícil, como queda claro de la lectura del voto disidente del ministro Fernández Fredes cuando hace ver que allí donde la Constitución ha querido imperar una indemnización al daño moral lo ha dicho expresamente, no pudiendo por tanto afirmarse la existencia de un mandato constitucional a la indemnización del daño moral en todo caso). En el caso del rol No 577-06, la normatividad de la Constitución queda completamente ocluida por la forma en que el Tribunal Constitucional maneja el concepto de contaminación; al señalar que ella sólo es jurídicamente apreciable en la trangresión a los parámetros fijados por el legislador, abdica completamente de la construcción de un estándar constitucional de contaminación: en el fondo, el Tribunal sostiene que, si no se han fijado parámetros legales de la misma, ella no existe. Considerando $13^{\circ}$ : "Que no es admisible sostener que el Decreto Supremo impugnado legaliza una contaminación histórica, como afirman los requirentes, pues jurídicamente contaminación no es cualquier 
impacto o alteración ambiental sino la situación que supera los parámetros ambientales establecidos, y la norma que se ataca no contiene una autorización de tal indole. En tal sentido, y a pesar de que no tiene el carácter de una ley interpretativa de la Constitución, no puede prescindirse de los conceptos que formula - "para todos los efectos legales"- el artículo $2^{\circ}$ de la Ley $N^{\circ} 19.300$, sobre bases generales del medio ambiente, para apreciar si la presencia de un contaminante es más que un impacto o alteración del ambiente y merece ser calificada de contaminación. Dicho artículo define en su letra k) "impacto ambiental" como "la alteración del medio ambiente, provocada directa o indirectamente por un proyecto o actividad en un área determinada", mientras que "contaminación", según la letra c) del mismo artículo, es "la presencia en el ambiente de sustancias, elementos, energía o combinación de ellos, en concentraciones o concentraciones y permanencias superiores o inferiores, según corresponda, a las establecidas en la legislación vigente". De tal forma, mientras no se aprueben las normas de calidad ambiental respectivas que determinen objetivamente los parámetros dentro de los cuales es admisible en el ambiente una sustancia o elemento, no corresponde hablar de contaminación, a menos que se acredite inequivocamente la presencia en el ambiente de un contaminante, en términos tales que constituya un riesgo cierto a la vida, a la salud de la población, a la conservación del ambiente o la preservación de la naturaleza, o bien que exista una situación de pública e indiscutida notoriedad de la presencia gravemente nociva en el ambiente de un contaminante".

Con ello, de paso, deja sin fuerza normativa el deber contenido en el artículo 19 No 8 C.Pol. (ya que el Estado sólo deberá velar porque este derecho no sea afectado en la medida en que el mismo defina lo que es contaminación). Esto nos conduce a la tercera categoría de casos en que se debilita la fuerza normativa de la Constitución.

3. Debilitamiento de la fuerza normativa vía interpretación de determinados preceptos constitucionales.

La fuerza normativa de la Constitución se ve debilitada también cuando el Tribunal, a partir del manejo que hace de los términos o conceptos de la Constitución, enerva el efecto normativo que podría atribuirse a sus disposiciones. Ello ha ocurrido, tras la reforma del año 2005, al menos en dos ocasiones: coincidentemente, en ambos casos se ve afectada la fuerza normativa que podría haber desplegado el artículo 8 C.Pol.

El primer caso se produce con ocasión de un requerimiento de inaplicabilidad en contra del artículo 13 de la Ley Orgánica Constitucional de Bases Generales de la Administración del Estado, que establece, entre las causales por las cuales se puede negar la entrega de documentos o antecedentes de carácter público, el que su conocimiento pudiese afectar derechos o inte- 
reses de terceras personas. Tras la reforma del ańo 2005, se observa que el artículo $8^{\circ}$ C.Pol. sólo permite como excepción al principio de publicidad el que la ley disponga la reserva o secreto de actos, resoluciones, fundamentos o procedimientos el caso en que éstos puedan afectar el debido cumplimiento de los órganos respectivos, los derechos de las personas, la seguridad de la Nación o el interés nacional; de este modo, aquella parte del artículo 13 de la Ley Orgánica Constitucional de Bases Generales de la Administración del Estado que permite la denegación de acceso a los documentos por afectar el interés de terceras personas aparecía, según el requirente, como una excepción en pugna con las acotadas causales expresadas. Justamente la idea de la reforma (promulgada en un momento en que se encontraba vigente el artículo 13 LOCBGAE. impugnado) había sido acotar las posibilidades de excepción al principio de publicidad, a aquellas que establece el actual artículo $8^{\circ} \mathrm{C}$.Pol. Sin embargo, el Tribunal decide utilizar una vía argumental en la que, echando mano principalmente de conceptos desarrollados en sede procesal, llega a concluir que la expresión “interés" puede asimilarse a la expresión "derecho".

El punto de inflexión en la argumentación del Tribunal puede identificarse con precisión en la omisión de una sola expresión, en el considerando $9^{\circ}$ de este fallo. En él, el Tribunal sostiene que: “...en base a los conceptos recordados, es posible sostener que el interés, en el ámbito jurídico, no se identifica necesariamente con la noción tradicional de derecho entendida como derecho subjetivo. No obstante ello también parece claro que la noción de interés representa una categoría reconocida progresivamente por los ordenamientos normativos para la protección de bienes juridicos que no pueden ampararse de la misma forma que los derechos subjetivos tradicionales".

La expresión omitida, que habría hecho correcta la afirmación del Tribunal, pero cuya exclusión le permite hacer la identificación que busca, es la palabra "procesal” que debió seguir a "en el ámbito jurídico". Tal y como dan cuenta los propios ejemplos doctrinarios que aporta el Tribunal, es en sede de los procedimientos jurisdiccionales, y parcialmente también en el caso de los procedimientos administrativos, donde resulta relevante aceptar como legitimados activos, junto con los titulares de derechos subjetivos, a quienes aparecen como detentadores de un interés legítimo. Pero aparece también de estas reflexiones que el sentido de las mismas es mantener la diferencia conceptual, la que se desarrolla justamente para dar cabida a los segundos en los procedimientos "en los que tengan interés". El Tribunal utiliza un argumento de pars pro toto y, sobre la base fundamental de estas consideraciones (y otras que no resultan determinantes) llega a concluir en su considerando $23^{\circ}$ que: "[...] puede colegirse que, al establecer el inciso segundo del artículo $8^{\circ}$ de la Constitución, las causales de 
reserva o secreto que exceptúan la plena aplicación del principio de publicidad de los actos y resoluciones de los órganos del Estado, de sus fundamentos y de los procedimientos que utilicen, entre las cuales se incluye que "la publicidad afectare [...] los derechos de las personas", la expresión "derechos" está siendo utilizada en el mismo sentido amplio que en el artículo $1^{\circ}$, inciso cuarto, de la Carta Fundamental, comprendiendo tanto la protección de derechos subjetivos o derechos en sentido estricto cuanto de intereses legitimos".

Con ello, el Tribunal disminuye notablemente la extensión o fuerza normativa del principio de publicidad contenido en el artículo $8^{\circ}$, al permitir que la ley establezca reserva o secreto de antecedentes públicos por afectar intereses de terceras personas. Hay que considerar que en todos los casos en que, como en el fallo rol No 634-06, una persona quiere evaluar la actuación que el órgano público ha tenido para con ella, en comparación con el trato dispensados a terceros, deberá solicitar al órgano respectivo los antecedentes de dichos terceros. Pues bien, de acuerdo al criterio aplicado por el Tribunal, estos terceros siempre podrán alegar un interés para evitar que dichos antecedentes sean hechos públicos. De este modo, el principio de publicidad se ve frustrado en una las dimensiones que quizás más relevancia pudiese tener, a saber, el control de la discriminación arbitraria por parte de los órganos públicos.

El segundo caso se da con la sentencia recaída en el procedimiento de control obligatorio de la antedicha Ley de Transparencia (o de acceso a la información pública), rol No 1051-08. Esta ley regula, entre otras cosas, el derecho de acceso a la información de los órganos de la Administración del Estado y las excepciones a la publicidad de la información. En el artículo 21 del proyecto de ley sometido al control del Tribunal Constitucional, se establecían las causales de secreto o reserva en cuya virtud podía denegarse total o parcialmente el acceso a la información. Respecto de las causales de afectación de debido cumplimiento de las funciones del órgano, afectación de los derechos de las personas y afectación de la seguridad de la Nación, los respectivos preceptos agregan una especificación estructurada en torno a la expresión "particularmente" (cuando [...] afecte a los derechos de las personas, particularmente cuando [...]); en el caso del interés nacional, la expresión utilizada es "en especial". El problema de esta redacción es que, así formuladas las excepciones, los enunciados particulares dentro de cada categoría no revisten el carácter de taxativos, quedando abierta la posibilidad de encontrar otros motivos, bajo la respectiva causal, que pudiesen motivar la denegación de acceso. Si bien es cierto la ley recoge una remisión a la regla constitucional en virtud de la cual las excepciones sólo podrán estar previstas en la misma ley o en otra de quórum calificado, en términos sistemáticos el artículo 21 está regulando, no a la ley u otras leyes, 
sino que al órgano administrativo y su posibilidad de denegar el acceso a la información. En este sentido, las expresiones "particularmente" y "en especial" que utiliza la ley, generan la posibilidad de argumentar facultades para que el órgano administrativo deniegue por otros motivos, amparados en la respectiva causal, pero no especificados en la ley. Ello debilita el sentido normativo del mandato del artículo $8^{\circ}$ en vistas a que las excepciones al principio de publicidad sean establecidas por ley de quórum calificado. No salva esta objeción la existencia de un procedimiento para recurrir ante el Consejo de Transparencia, en la medida en que, aun cuando éste llegue a pronunciarse sobre el tópico, seguirá incumplida la exigencia de ley de quórum calificado para estas excepciones. El Tribunal no se pronuncia sobre esta disposición por estimar que no corresponde al ámbito del control vía artículo 93 inciso $1^{\circ}$ No 1 . Esta decisión puede ser correcta (o no), pero en su efecto permite el ingreso al ordenamiento jurídico de las disposiciones que causan esta disminución de la fuerza normativa del artículo $8^{\circ}$. El voto disidente del Ministro Fernández Baeza es de destacar, por haber reparado acertadamente en este problema, y haber justificado, además, la facultad del Tribunal para examinar el proyecto en su totalidad.

La constatación de estos casos de debilitamiento de la fuerza normativa lleva a observar que la forma en cómo se articula la praxis legislativa o la actividad jurisdiccional con la esperada fuerza reguladora de un texto normativo plantea un problema específico, que no está solucionado, sino sólo planteado, con la referencia a la fuerza normativa de la constitución: ¿Cómo se construye la normatividad en el sistema jurídico, y qué elementos son necesarios para que dicha normatividad sea efectivamente desplegada a partir de dichos textos? O, en términos negativos ¿cómo se logra que los textos normativos no sean simplemente usados como pretextos de alguna construcción argumental cualquiera dirigida a producir la apariencia de una fundamentación?

\section{EL CONCEPTO DE NORMATIVIDAD DESDE EL PUNTO DE VISTA JURÍDICO}

Desde el momento en que se acepta que el texto debe ser interpretado a fin de fundar la decisión judicial, sea cual sea la terminología o nomenclatura que se utilice para describir esta relación entre un dato inicial (el texto de una ley, de un reglamento, de la constitución) y el resultado final (la afirmación sobre su sentido normativo) entonces es procedente, como lo señala Müller ${ }^{37}$, distinguir entre texto y norma. De esta distinción resulta

${ }^{37}$ MülLER, Friedrich, Juristische Methodik (5a edición, Berlin, Duncker \& Humblot, 1993), pp. 125 ss.. 
que la normatividad no es una cualidad de determinados textos o, que al menos, no les es inmanente, no se desprende de ellos. De manera resumida, su pensamiento sobre este punto se aprecia en el siguiente párrafo: "El texto normativo es una expresión lingüística, de la misma naturaleza que textos que no tienen carácter normativo. Su calidad como texto, en la perspectiva de una disposición jurídica vinculante no es consecuencia, sin más, de particularidades de la configuración del lenguaje o del contexto lingüístico. No es posible observar, a partir de la expresión lingüística de una proposición jurídica, si se trata de un precepto vigente "aquí y ahora", o bien actualmente vigente pero en otro Estado, de un precepto que se ha vuelto obsoleto, o una disposición del todo ficticia. Por eso, la expresión "corresponde a una norma" sólo puede significar que el texto normativo obliga al jurista, en términos jurídicos, a ubicarlo al inicio del proceso de concretización, en cuyo transcurso se construye la norma jurídica y en cuyo término es resuelto el caso. El texto normativo no puede ser normativo, él mismo, más allá de esta obligación; sólo puede contribuir a preparar entidades normativas (a saber, la norma jurídica y decisoria). Como expresión, como textos, las oraciones "El parlamento será elegido por cuatro años" y "El parlamento será elegido por cinco años" tienen el mismo valor desde el punto de vista de su posible normatividad. El hecho de que la primera de ambas oraciones se encuentre en el artículo $1^{\circ}$ inciso I primera oración de la ley Fundamental de Bonn no demuestra por sí mismo que sea él el que formule la regulación jurídica vigente. Y esto porque ni siquiera del texto completo de esta Ley Fundamental de Bonn, esto es, de sus particularidades lingüísticas, se deriva una normatividad de las fórmulas en cuestión. La normatividad resulta mucho más de circunstancias extra lingüísticas de naturaleza social y estatal; de un funcionamiento efectivo, de un reconocimiento en los hechos, de una actualidad real de este ordenamiento constitucional para las motivaciones dentro de su ámbito; en otras palabras, de circunstancias que, aun cuando se quisiera, no podrían ser fijadas en el texto normativo, en el sentido de una garantía a su actualización" 38 .

${ }^{38}$ Müller, cit. (n. 37), p. 125: "Der Normtext ist Sprachliche Aussage, sprachlicher Text wie Texte nicht-normbezogener Art auch. Seine Qualität als Text in der Perspektive auf eine verbindliche Rechtsvorschrift hin folgt nich aus Besonderheiten der Sprachgestalt oder aus solchen des sprachlichens Zusammnehangs. Der sprachlichen Formulierung eines Rechtsatzes is nich anzusehen, ob sie zu einer hier und jetzt "geltenden" Vorschrift, zu einer zwar jetzt, aber in einem anderen Staatsverband geltenden, zu einer obsolete gewordenen oder zu einer vollständig fiktiven Rechtsnorm gehört. 'Zu einer Norm gehören' kann dabei nur heißen: der Normtext verpflichtet den Juristen rechtlich dazu, ihn an den Anfang des 
Por normatividad se entiende entonces, en este contexto, la cualidad de ciertos textos en virtud de la cual se incorporan en el esquema comunicativo del poder político, y por la cual se les reconoce el carácter de dato inicial para la construcción de criterios (normas) relativos a las decisiones sobre coordinación de los comportamientos que en última instancia conciernen a la aplicación de la coacción ${ }^{39}$. Con ello, la idea de normatividad vincula la función comunicativa de los textos normativos como instrumentos de la comunicación de mensajes imperativos, con su aplicación, lo que significa, en primera línea, con su interpretación por parte de aquellos llamados a tomar esas decisiones. La normatividad vincula la condición lingüística de los mensajes imperativos con su función como instrumentos de regulación del comportamiento en el marco del poder político institucionalizado o, dicho de manera sintética: la normatividad es la función que se pretende de los textos normativos en el esquema comunicativo del poder político institucionalizado ${ }^{40}$. Por sí mismos, los textos no producen nada. Su

Konkretisierungsvorgangs zu setzten, in dessen Verlauf die Rechtsnorm gebildet und an dessen Ende der Fall entschieden wird. Der Normtext kann, über diese Verpflichtungswirkung hinaus, nicht schon selbst normativ sein, nur spätere Größen (Rechts- und Entscheidangsnorm) vorbereiten helfen. Als sprachliche Aussage, als Texte, sind die Sätze: 'Der Bundestag wird auf vier Jahre gewählt' und 'Der Bundestag wird auffünfJahre gewählt' im Hinblick auf ihre mögliche Normativität gleichwertig. Auch die Tatsache, daß sich der erste der beiden Sätze in Artículo 39 Abs. 1 Satz 1 des Bonner Grundgesetzes sprachlich widerfindet, beweist noch nicht, daß er es ist, der die 'geltende' rechtliche Regelung formuliert. Denn auch aus dem Gesamttext dieses Bonner Grundgesetzes, d.h.hier: aus seinen sprachlichen Eigenschaften, geht einer Normativität der fraglichen Formulierung nicht hervor. Die Normativität folgt vielmehr aus außersprachlichen Gegebenheiten staatlich-gesellschaftlicher Art: aus einem tatsächlichen Funktionieren, aus einem tatsächlichen Anerkanntsein, aus einer tatsächlichen Aktualität dieser Verfassungsordnung für empirische Motivitationen in ihrem Bereich: also aus Gegebenheiten, die, selbst wenn man es wollte, im Sinn der Garantie ihres Zutreffens im Normtext gar nicht fixierbar wären”.

${ }^{39}$ Esta idea parece ya estar presente en Heller, Hermann, Staatslehre (1983), pp. 220, 221 y 298 ss. Este autor destaca la importancia de la dogmática jurídica para el despliegue de la normatividad.

${ }^{40}$ Busse, Dietrich, Recht als Text: linguistische Untersuchungen zur Arbeit mit Sprache in einer gesellschaftlichen Institution (Tübingen, 1992), pp. 91-92: "No se puede reconocer, entonces, a un texto como ejemplar de la "función normativa de los textos" sin conocimiento del contexto de utilización de dicho texto. Esto lo demuestran todos los intentos de definición de la función normativa de los textos, o de actos de habla "regulativos" "directivos" o "declarativos" que no pueden pasar sin una referencia al indefinido hecho social de la normatividad. Lo que sea una norma, o tenga carácter normativo, nos es dado por nuestro conocimiento sobre instituciones sociales y su actuar, dentro de cuyo contexto se produce la normatividad. Con otras palabras, no reconocemos a un texto "por sí mismo" como normativo, sino 
"activación normativa" se da cuando son incorporados en el esquema comunicativo de un conjunto de comportamientos en que las acciones individuales, incluyendo aquellas que pueden denominarse "aplicación de textos", son motivadas y dirigidas a partir de decisiones sobre el sentido atribuible a dichos textos. Esto puede demostrarse fácilmente: si un tribunal resuelve un asunto sin considerar $o$ atribuir fuerza normativa a un texto que, de acuerdo al propio sistema, debe tenerlo, dicha fuerza sólo podrá ser actualizada con ocasión de la invalidación o modificación de la respectiva resolución, por parte de los integrantes de otro tribunal, que conozca del asunto a través de alguno de los recursos que contempla la ley. Si ello no ocurre y, por ejemplo, el juzgador no es tampoco perseguido por su responsabilidad criminal por el correspondiente prevaricato, considerada su conducta como fallar contra ley (artículo 223 No 1 C. Penal) o dictar sentencia manifiestamente injusta (artículos 224 No 1 y 225 No 1 C. Penal), entonces el correspondiente texto, de normativo, sólo tiene el propósito, pero no la fuerza; carece de normatividad efectiva en el sistema institucional: es, como suele decirse tan gráficamente, letra muerta ${ }^{41}$. La relación entre el texto y la decisión nos remite, a su vez, a un contexto de práctica social institucionalizada, en la medida en que la descripción doctrinal del correspondiente tipo penal de prevaricato se explica como aquella opción interpretativa que no es teóricamente justificable según métodos admitidos por la ciencia jurídica ${ }^{42}$.

Es importante destacar en este punto lo siguiente. Si texto y norma son entidades diferenciables, y las normas son producidas intelectualmente en un proceso que involucra atribución de significado a los textos, la normatividad de éstos, en términos de su contenido, no es previa, sino que producto de dicho proceso. De aquí es que resulta incorrecta una forma

que inserto en un contexto pragmático institucional" ["Man kann also einen Text als Exemplar der 'normativen Textfunktion' nicht ohne Kenntnis des Gebrauchzusammenhangs des Textes erkennen. Dies machen sämtliche Definitionsversuche der 'normativen Textfunktion' oder der 'regulativen', 'direktiven', 'deklarativen' Sprechakte deutlich, die alle nicht ohne Verweis auf das undefiniert bleibende gesellschaftliche Faktum 'Normativität' auskamen. Was 'Norm' oder 'normativ' heißt, ist uns durch unsere Kenntnis der gesellschaftlichen Institutionen und ihres Wirkens, in denen diese Normativität hergestell wird, immer schon bewußt; d.h.wie erkennen einen Text nicht 'aus sich selbst heraus' als normativ, sondern nur eingebettet in einen (institutionellen) Handlungszusammenhang"].

${ }^{41}$ Bulnes Aldunate, cit. (n. 4), p. 142, usa precisamente esta expresión para aludir a la pérdida de fuerza directamente vinculante de la constitución.

${ }^{42}$ Rodríguez Collao, Luis - Ossandon Widow, María Magdalena, Delitos contra la función pública (2a edición actualizada, Santiago de Chile, Editorial Jurídica de Chile, 2008), p. 197. 
de hablar que califica, a partir de la vaguedad o indeterminación de un texto el carácter de vaguedad o indeterminación de las respectivas normas o de los respectivos contenidos normativos ${ }^{43}$. Como norma jurídica se considera aquí sólo aquella categoría que permite evaluar en términos disyuntivos un comportamiento como conforme o no conforme a una regla (y eventualmente asociar una sanción a determinado comportamiento). La norma misma puede permitir mayores o menores espacios de libertad, pero para ser aplicable como tal siempre debe permitir un juicio alternativo sobre un comportamiento como ajustado o contrario a la respectiva norma. Imperativos que permiten ser "cumplidos" en mayor o menor grado, como principios, metas y programas, no constituyen normas. Allí donde, en el ámbito jurídico, los principios y otras categorías similares son introducidos con una posición autónoma (y no como parte del razonamiento de construcción normativa), no reemplazan a la norma, sino que simplemente interrumpen la cadena argumental según la cual se le atribuye al texto un contenido normativo. Una teoría de la normatividad de la constitución que quiera mantener dicha normatividad debe tener en claro que el documento constitucional debe ser manejado de tal manera que conserve su función jurídica, lo que significa, que su interpretación debe estar al servicio de la construcción de normas (y no de otras categorías de menor precisión deóntica).

Es aquí donde la noción de normatividad $-y$ la consiguiente fuerza normativa que pueda desplegar un texto-se relaciona de manera directa con la función de las construcciones que aporten un marco de referencia para el actuar (las decisiones y fundamentaciones) de los operadores jurídicos. Sin dicho marco de referencia-que se extiende desde el sistema conceptual sobre el derecho y el sentido de las entidades normativas hasta las dogmáticas especiales elaboradas sobre la base de los respectivos preceptos- se hace imposible acotar o controlar las afirmaciones que pueda realizar el operador jurídico ${ }^{44}$. El fundamento de la crítica postura de Atria Lemaitre respecto de la justicia constitucional (o la revisión judicial, en la termino-

${ }^{43}$ Como por ejemplo, la difundida concepción de que la estructura de los textos constitucionales no permite su manejo como "reglas" sino que como "principios".

${ }^{44}$ Como dice Accatino Scagliotti, Daniela, La interpretación de los derechos fundamentales y la seguridad juridica. Una mirada a la práctica constitucional chile$n a$, en Bordalí Salamanca, Andrés (coordinador), Justicia constitucional y derechos fundamentales (Santiago de Chile, LexisNexis, 2006), p. 20, lo que produce la falta de una dogmática jurídica en el plano constitucional es que los conceptos jurídicos pierden su capacidad de aportar criterios públicos de valoración. Esto vale tanto para la Constitución en su dimensión jurídica -en cuanto base de construcción de normas- cuanto en su dimensión política -como base de la legitimación del poder político institucionalizado-. 
logía usada por él) puede radicarse aquí; como lo demuestran alguno de los ejemplos mencionados, las decisiones de la jurisdicción constitucional, no contenidas o limitadas por un adecuado desarrollo dogmático, aparecen como pura decisión política, objetable desde la perspectiva de un sistema democrático ${ }^{45}$. La gran diferencia que presenta en este aspecto el manejo las fuentes escritas del derecho constitucional, en comparación con, por ejemplo, las del derecho privado ${ }^{46}$, es que en este último caso la construcción doctrinaria es mucho más densa y saturada en el desarrollo histórico y los co-textos de producción normativa, doctrinaria y jurisprudencial. En cambio, las constituciones escritas, desde sus inicios, pero mucho más con el advenimiento de la judicialización de su aplicación, han quedado en medio de las controversias políticas transformadas en batallas semánticas, sin referencias doctrinales u otros co-textos que permitan su adecuada disciplina. El derecho penal ha sido mucho más abierto (o sincero, si se quiere) al introducir de manera expresa en su sistema de fuentes el rol que cumple el desarrollo dogmático, al mencionar, dentro de las fuentes en las cuales un tribunal penal puede fundar la calificación jurídica de los hechos y sus circunstancias, a la doctrina (artículo 342 lit. d) del Código Procesal

${ }^{45}$ Atria Lemaitre, Fernando, Revisión judicial: el sindrome de la víctima insatisfecha, Estudios Públicos 79 (Invierno de 2000), p. 389: "En Chile no hay reflexión profunda sobre lo que las garantías constitucionales significan y cómo ellas deben ser aplicadas a casos complejos. Mal podría esperarse de nuestros tribunales que desarrollaran una doctrina que reconozca la 'influencia hermenéutica de la totalidad de los derechos constitucionales' cuando nuestros constitucionalistas tampoco lo han hecho. El paupérrimo desarrollo de nuestra dogmática constitucional no es un asunto baladí: la idea central de entregar a instancias jurisdiccionales más que explícitamente políticas la última palabra en la interpretación de la constitución tiene que ver con la idea de que éstas intentarán decidir lo que la constitución demanda con cierta distancia de los conflictos políticos que crean esos problemas. A falta de criterios dogmáticos, sin embargo, el órgano jurisdiccional que corresponda no podrá sino aplicar criterios políticos [...]. Y en estas circunstancias la existencia de una instancia llamada 'jurisdiccional' no agrega nada al control de constitucionalidad ya producido a nivel de las instancias representativas. Si el objetivo del control jurisdiccional de constitucionalidad es lograr la "sujeción de la política al derecho" [...], en las circunstancias actuales mantener el 'sistema' chileno implica reemplazar la política democrática del parlamento por la política oscura, corporativa y conservadora de los tribunales".

${ }^{46}$ U otras "áreas más urbanizadas dogmáticamente", expresión de ATRIA LEMAITRE, Fernando, Seguridad juridica y derechos fundamentales: sobre predictibilidad y autogobierno, en Bordalí Salamanca, Andrés (coordinador), Justicia constitucional $y$ derechos fundamentales (Santiago de Chile, LexisNexis, 2006), p. 11, que encuentro particularmente expresiva de aquello que se quiere decir aquí. 
Penal). Y nótese que esto sucede en aquella rama del derecho de un grado importante (quizás el mayor) de desarrollo dogmático.

\section{FUERZA NORMATIVA Y SISTEMA DE FUENTES}

La inclusión de un texto como dato base para la producción de normas de las cuales se predicará supremacía normativa, y a las cuales en su conjunto (como constitución en sentido jurídico) se les atribuye la función de fundar la validez del ordenamiento jurídico, tiene efectos gravitantes en el sistema de fuentes, a tal punto que puede decirse que, desde el momento en que tiene lugar tal inclusión, el concepto y estructura del sistema de fuentes será una consecuencia del concepto de constitución y la función que se le atribuya en lo que respecta a los efectos normativos -o fuerza normativa, si se quiere- que la propia constitución despliegue en el sistema de fuentes. Esta afirmación puede ser fácilmente entendida a partir de una comparación con la idea de derecho común. En distintos lugares de la Europa medieval en transición hacia el Estado moderno (s. XIV a XVI), existieron, durante mucho tiempo, y junto con costumbres locales y estatutos personales, datos normativos provenientes de una incipiente legislación monárquica, de la recepción del derecho romano y su posterior elaboración por glosadores, postglosadores y comentaristas y, dependiendo del caso, del derecho canónico. Frente a esta pluralidad de fuentes y posibilidades aparece la referencia regular a un derecho común (en sentido y con contenidos diferentes, según el caso), al cual se recurre, al menos, con carácter supletorio en caso de vacío o laguna en las demás fuentes. Si se compara esta situación con el efecto que tiene sobre el sistema de fuentes la afirmación de la eficacia directa de la constitución, por una parte, y del efecto entre particulares de los derechos fundamentales, por otra (en especial si son considerados y manejados como "principios"), se puede apreciar como resultado que la constitución no sólo afecta el sistema de fuentes propio del derecho público (regulador de la constitución, funciones, atribuciones, procedimientos y formas propios del ejercicio del poder público) sino que también el del derecho privado, desde el momento en que toda regulación, toda regla jurídica queda sometida al imperio de esta suerte de nuevo "derecho común" que se viene a aplicar siempre, y no con carácter supletorio, sino de supremacía. Los principios de cada rama del derecho, como elementos del propio sistema de fuentes que le da identidad, 
empiezan a ser reemplazados - o desplazados- por la interpretación de los derechos constitucionales, precisamente como principios ${ }^{47}$.

Para un concepto de constitución que quiere ver en la carta fundamental no solo el fundamento último, sino que inmediato de todas las fuentes del derecho, todo el sistema de fuentes queda irradiado por la constitución y por lo tanto, sometido a ella. Con esto, de paso, hay fuentes que desparecen como fuentes autónomas, o al menos pierden su sentido original, como es el caso de la equidad -que a partir de la entrada en vigencia de una constitución así concebida sólo podría entenderse como concreción o actualización de valores constitucionales. De este modo, tanto en su función de fuente primaria (en el caso de los árbitros arbitradores, artículo 223 inciso $3^{\circ} \mathrm{COT}$.) como supletoria de ley escrita en el derecho privado (los principios de equidad en los cuales el juez puede fundar su fallo según el artículo 170 No 5 del CPC.), y en su función interpretativa (la equidad natural a la que alude el artículo 24 del Código Civil), la equidad perdería parte importante de su contenido tradicional que pasaría a ser desplazado por consideraciones de justicia o ponderación basadas en "el orden objetivo de valores" 48 establecido por los preceptos sobre derechos fundamentales contenidos en la Carta. Cosa similar sucedería con ese borde de contacto que el derecho positivo abre a las convicciones éticas prevalecientes en la sociedad ${ }^{49}$ cuando la técnica legislativa emplea una referencia a estándares de moral o de buenas costumbres. De hecho, es justamente aquí donde se produce originalmente el ingreso a la idea del efecto de irradiación de la constitución y del efecto horizontal de los derechos fundamentales ${ }^{50}$. La costumbre jurídica, a pesar de ser una regla de derecho construida a partir de ciertos hechos - las conductas que se reiteran en el tiempo-, tendría que pasar a ser examinada a la luz de su constitucionalidad, sin que resulte claro quién debe realizar este examen en los casos de costumbre según la ley. Para aquellos que niegan la posibilidad del control difuso, no se ve por qué en estos casos el tribunal de la instancia debiese estar facultado para declarar que la regla de derecho consuetudinaria, construida de acuerdo al llamado

${ }^{47}$ BöCKEnförde, Ernst Wolfgang. Die Eigenart des Staatsrechts und der Staatsrechtswissenchaft, en BöcKENFÖRDE, Ernst Wolfgang, Staat, Verfassung, Demokratie (Frankfurt am Main, 1991), p. 23.

${ }^{48}$ Para utilizar la expresión de la jurisprudencia alemana recibida en Chile junto con la teoría del efecto horizontal de los derechos fundamentales en Chile.

${ }^{49}$ En términos prácticos, a aquellas convicciones apreciadas y valoradas por el juzgador; pero esto no resta validez a la afirmación que se sostiene aquí.

${ }^{50} \mathrm{El}$ caso "Lüth", del que conoció el Tribunal Constitucional Federal alemán, puerta de entrada a estos tópicos, giraba justamente en torno a la relación entre una cláusula de buenas costumbres, contenida en el Código Civil, y la aplicación de preceptos de la Ley Fundamental de Bonn. 
legal, es inválida por ser inconstitucional; pero tampoco se avizora cómo llevar esta hipótesis al control del Tribunal Constitucional.

Sin embargo, no sólo estos componentes del sistema de fuentes -que podrían estimarse excepcionales desde la perspectiva de conjunto- se ven afectados, sino que otros de mucha mayor importancia, como lo son los principios propios de cada una de las ramas del derecho y que sintetizan opciones jurídico-políticas informadoras de dichas ramas y que se han desarrollado históricamente al margen de la influencia constitucional. Así, por mencionar un ejemplo, la idea de autonomía de la voluntad en el campo de las obligaciones. Tradicionalmente, la capacidad de los sujetos de derecho de obligarse en virtud de su autonomía contractual estuvo estructurada bajo un régimen de libertad de contratación entendida como libertad para contratar o no, para elegir el co-contratante y para configurar el respectivo contrato. Esta libertad se articuló en el tiempo con una cantidad de reglas supletorias de la voluntad de las partes, y el surgimiento de una cierta cantidad de normas limitativas de dicha libertad, ya fuesen en su carácter de orden público, ya fuesen por tratarse de disposiciones sobre contratación forzosa o dirigida. Sin embargo, bajo el concepto de constitución que se comenta, el ámbito de la autonomía de la voluntad en el que todavía rige la libertad contractual se ve afectado y sometido a una reserva funcional, entendida como el deber de ejercer dicha autonomía al servicio de la finalidad de satisfacción de derechos fundamentales, como queda claro al tenor de los siguiente considerandos de la sentencia del Tribunal Constitucional recaída en la causa rol No 976-07: considerando 40": "Que el deber de los particulares de respetar y promover los derechos inherentes a la dignidad de la persona persiste, inalterado, en las relaciones convencionales entre privados, cualquiera sea su naturaleza. Sostener lo contrario implicaría admitir la posibilidad de que, invocando la autonomía de la voluntad, tales derechos y, a su vez, la dignidad de la persona, pudieran ser menoscabados o lesionados en su esencia, interpretación que, a la luz de lo ya explicado, se torna constitucionalmente insostenible"; considerando $41^{\circ}$ : "Que lo razonado resulta aun más evidente en los casos en los que la relación convencional entre sujetos de derecho privado halla reconocimiento o amparo constitucional, sea directo o indirecto pero inequivoco, como medio a través del cual uno de ellos, en cuanto manifestación del principio de subsidiariedad articulado en el Código Politico, da satisfacción al ejercicio legitimo de derechos esenciales, en este caso de la contraparte, como sucede con el contrato de salud, celebrado entre una Institución de Salud Previsional y un particular determinado, respecto del atributo asegurado a este último en el artículo 19, No 9, inciso final, de la Carta Politica".

Como se ve, un tal concepto de la función de los derechos fundamen- 
tales en la Constitución altera completamente la idea de autonomía de la voluntad del ámbito del derecho privado, en la medida en que, desde un punto de vista técnico-jurídico, transforma a los particulares en verdaderos órganos al servicio de la satisfacción de los derechos fundamentales de otro. Por si quedara dudas de la extensión en que se produce una alteración de los principios tradicionales del derecho privado, cabe mencionar que en este mismo fallo la declaración de inaplicabilidad del precepto legal impugnado pone en entredicho el principio de fuerza obligatoria de los contratos, desde el momento que acepta que las circunstancias fácticas que puedan incidir en la capacidad de pago de una de las partes obligadas por el contrato ${ }^{51}$, cuando la interrupción de las prestaciones de la otra parte pudiese afectar un derecho constitucional, son relevantes para declarar la correspondiente inaplicabilidad por inconstitucionalidad del precepto que habilita a una de las partes para exigir un efecto específico del respectivo contrato. En la especie se trataba de la facultad de modificar unilateralmente el contrato, como contrapartida a la supresión del derecho a poner término al contrato, frente a la libertad que para ello conservaba su contraparte.

Esta forma de entender la relación entre constitución y sistema de fuentes no es la única -ni la más recomendable-. Una apreciación más conforme con la función que la constitución debe cumplir no la concibe sin más como sustento de validez de todo el sistema de fuentes, sino simplemente como fuente de la juridicidad de una serie de competencias que, a su vez, pueden estructurar un ordenamiento jurídico con ámbitos de autonomía para una serie de fuentes diferenciadas. La fuerza normativa de la constitución no implica una supresión o desplazamiento de dichas fuentes: ellas pueden desarrollar sus propios principios y expresar fuentes materiales del derecho que no necesariamente son las que corresponden al proceso político, sino que al desarrollo social de la comunidad, o a las necesidades e intereses de las partes en una dimensión negocial. El sistema de fuentes del derecho es bastante más complejo que lo que se puede apreciar en una pirámide normativa que va desde la constitución a la sentencia o al acto de aplicación, pasando por la ley y por el reglamento y otras disposiciones de rango intermedio. El Estado puede pretender monopolizar la producción del derecho, pero ese monopolio no implica necesariamente el desconocimiento de las posibilidades configuradoras de un ordenamiento jurídico desde la propia sociedad, y de las partes en los negocios jurídicos Parece ser necesario reconocer que las distintas fuentes del

${ }^{51}$ No constitutivas de, ni conceptualmente cercanas a la fuerza mayor o el caso fortuito, ni al cambio fundamental de las circunstancias, ni a la imposibilidad de cumplimiento o cualquier otro tópico discutido en el ámbito del derecho de las obligaciones que permita eximir a una de las partes del deber de cumplir su obligación. 
derecho cumplen funciones diversas en la construcción del ordenamiento jurídico, y no parece conveniente reemplazar un instrumental diferenciado y operativo de distintas fuentes, adecuado a requerimientos diversos de los ámbitos pragmáticos que se pretende disciplinar a través del derecho, por una sola constitución manejada, ya sea de manera unitaria por un solo tribunal -que vendría siendo entonces el único tribunal verdadero de la nación- o por una pluralidad de tribunales que, aún peor, darían en el papelero con el principio de unidad de la constitución, so pretexto de su actualización normativa. Aun cuando el capitán de una nave sea el superior tanto del primer oficial como del mecánico de a bordo, no se espera que las orientaciones que dé para la navegación (por ejemplo, calmada y sin prisas) deban aplicarse a la actividad de este último cuando observa una fuga masiva de lubricante en las máquinas.

\section{CONCLUSIONES}

La idea de fuerza normativa de la constitución, comúnmente aceptada en la doctrina y la jurisprudencia nacional, es una noción de múltiples contenidos que no se encuentran debidamente acotados en su uso argumental, y cuya pluralidad no contribuye a racionalizar y concretar las propias exigencias que se estima derivadas de ella. Su desarrollo en el plano jurídico, bajo la idea de eficacia directa, relega a un segundo plano la cuestión constitucional básica, que consiste en determinar las condiciones bajo las cuales la constitución es capaz, efectivamente, de ser un elemento regulador de las luchas por el poder en el esquema institucional. Un examen de nuestra práctica constitucional demuestra que al menos en el plano de la distribución de las competencias normativas, nuestra realidad institucional está lejos de dar cuenta de una verdadera fuerza normativa de la constitución. Por otro lado, los efectos de la invocación de esta idea, en vez de contribuir a dar unidad y racionalidad al sistema de fuentes, conllevan el peligro de destruirlo, sustituyendo cada vez más el sofisticado instrumental del derecho común y de las distintas ramas del derecho por una especie de referencia vaga y genérica a principios constitucionales que quedan entregados a la decisión caso a caso del juez constitucional y exentos de toda posibilidad de control. Se hace necesario, por tanto, reubicar la idea de fuerza normativa de la constitución en su punto de origen, como tópico del análisis de los aspectos político-jurídicos necesarios para lograr que la Constitución despliegue una efectiva fuerza regulatoria; y a partir de ello dotar de un contenido efectivo a la noción de fuerza normativa de la constitución en el plano jurídico, a través del desarrollo y disciplina de la labor dogmática, a fin de lograr que el texto constitucional efectivamente 
sirva de contención, y no sólo de pretexto, para las decisiones jurisdiccionales, en especial las de la jurisdicción constitucional.

[Recibido el 29 de abril y aceptado el 15 de mayo de 2009].

\section{BIBLIOGRAFÍA}

Accatino Scagliotti, Daniela, La interpretación de los derechos fundamentales y la seguridad jurídica. Una mirada a la práctica constitucional chilena, en BORDALí Salamanca, Andrés (coordinador), Justicia constitucional y derechos fundamentales (Santiago de Chile, LexisNexis, 2006), pp. 17-29.

Aldunate Lizana, Eduardo, Derechos fundamentales (Santiago, LegalPublishing, 2009).

Aros Chia, Rodrigo Marcelo, La fuerza normativa de la Constitución: Un principio vinculante de la judicatura constitucional, en Revista de Derecho Público 66 (Universidad de Chile, 2004), pp. 145-161.

Atria Lemaitre, Fernando, Revisión judicial: el sindrome de la víctima insatisfecha, Estudios Públicos 79 (Invierno de 2000), pp. 347-402.

Atria Lemaitre, Fernando, Seguridad jurídica y derechos fundamentales: sobre predictibilidad y autogobierno, en Bordalí Salamanca, Andrés (coordinador), Justicia constitucional y derechos fundamentales (Santiago de Chile, LexisNexis, 2006), pp. 7-16.

BöCKEnFöRdE, Ernst Wolfgang. Die Eigenart des Staatsrechts und der Staatsrechtswissenchaft, en Böckenrörde, Ernst Wolfgang, Staat, Verfassung, Demokratie (Frankfurt am Main, 1991), pp. 11-28.

Bordalí Salamanca, Andrés, La unidad en la interpretación jurisdiccional de los derechos fundamentales: una tarea pendiente en el derecho chileno, en Revista Chilena de Derecho 34 (Pontificia Universidad Católica de Chile, septiembre - diciembre de 2007), pp. 517-538.

Bulnes Aldunate, Luz, La fuerza normativa de la Constitución, en Revista Chilena de Derecho (Pontificia Universidad Católica, 1998), "Número Especial” pp. 137-142.

Busse, Dietrich, Recht als Text: linguistische Untersuchungen zur Arbeit mit Sprache in einer gesellschaftlichen Institution (Tübingen, 1992).

Cea Egaña. José Luis, Derecho constitucional chileno (2a edición actualizada, Santiago, Ediciones de la Universidad Católica de Chile, 2008), I.

Cea Egaña. José Luis, Sistema constitucional de Chile. Sintesis crítica (Valdivia, Universidad Austral de Chile, 1999).

Fernández González, Miguel Ángel, La fuerza normativa de la Constitución, en Revista de Derecho Público 63 (Universidad de Chile, 2001), pp. 77-102.

García Amado, Juan Antonio, El juicio de ponderación y sus partes. Una crítica, en Alexy, Robert, Derechos sociales y ponderación (Madrid, Fundación Coloquio Jurídico Europeo, 2007), pp. 249-331.

Heller, Hermann, Staatslehre (1983).

Hesse, Konrad, La fuerza normativa de la Constitución, en Hesse, Konrad Escritos de 
Derechos Constitucional (2a edición, Madrid, Centro de Estudios Constitucionales, 1992), pp. 55-78.

MüLLER, Friedrich, Juristische Methodik (5a edición, Berlin, Duncker \& Humblot, 1993).

Rodríguez Collao, Luis; Ossandón Widow, María Magdalena, Delitos contra la función pública (Santiago de Chile, Editorial Jurídica de Chile, 2a edición actualizada, 2008).

Silva bascuñán, Alejandro, Tratado de Derecho constitucional (Santiago de Chile, Editorial Jurídica de Chile, 1997), IV.

Weinstein, Graciela, La naturaleza jurídica del auto acordado, en Revista de Derecho Procesal 1 ( Universidad de Chile, 1971), pp. 5-34.

Zapata Larraín, Patricio, Justicia constitucional (Santiago de Chile, Editorial Jurídica de Chile, 2008).

ZúñIga Urbina, Francisco, Corte Suprema y sus competencias. Notas acerca de su potestad normativa (Autos Acordados), en Ius et Praxis 4 (1998) 1, pp. 221-234. 